\title{
Religiousness and depression: Evidence for a main effect and the moderating influence of stressful life events
}

\author{
Timothy B. Smith \\ Brigham Young University, tbs@byu.edu \\ Michael E. McCullough \\ University of Miami, mmccullough@umiami.ir.miami.edu \\ Justin Poll \\ Brigham Young University
}

Follow this and additional works at: https://scholarsarchive.byu.edu/facpub

Part of the Counseling Psychology Commons, and the Religion Commons

\section{Original Publication Citation}

Smith, T. B., McCullough, M. E., \& Poll, J. (2003). Religiousness and depression: Evidence for a main effect and the moderating influence of stressful life events. Psychological Bulletin, 116, 614-636.

\section{BYU ScholarsArchive Citation}

Smith, Timothy B.; McCullough, Michael E.; and Poll, Justin, "Religiousness and depression: Evidence for a main effect and the moderating influence of stressful life events" (2003). Faculty Publications. 2027. https://scholarsarchive.byu.edu/facpub/2027

This Peer-Reviewed Article is brought to you for free and open access by BYU ScholarsArchive. It has been accepted for inclusion in Faculty Publications by an authorized administrator of BYU ScholarsArchive. For more information, please contact ellen_amatangelo@byu.edu. 
Running head: Religiousness and Depressive Symptoms

Smith, T. B., McCullough, M. E., \& Poll, J. (2003). Religiousness and depression: Evidence for a main effect and the moderating influence of stressful life events. Psychological Bulletin, 116, 614-636.

\author{
Religiousness and Depression: \\ Evidence for a Main Effect and \\ the Moderating Influence of Stressful Life Events
}

Timothy B. Smith

Brigham Young University

Michael E. McCullough

University of Miami

Justin Poll

Brigham Young University

Date revision submitted: December 19, 2002

Smith, T. B., McCullough, M. E., \& Poll, J. (2003). Religiousness and depression: Evidence for a main effect and the moderating influence of stressful life events. Psychological Bulletin, 116, 614-636. 


\begin{abstract}
Using meta-analytic methods, the association between religiousness and depressive symptoms was examined with data from 147 independent investigations (total $\underline{N}=98,975)$. Across all studies, the correlation between positive religiousness and depressive symptoms was -.094, indicating that greater religiousness is associated with fewer symptoms. The results were not moderated by the demographic variables of gender, age, or ethnicity, but the religiousnessdepression link was stronger in studies involving people who were undergoing stress due to recent life events. The results were also moderated by the type of measure of religiousness used in the study, with extrinsic religious orientation and negative religious coping (e.g., avoiding difficulties through religious activities, blaming God for difficulties) associated with higher levels of depressive symptoms, the opposite direction from the overall findings. The religiousness-depression association appears to be a statistically weak but reliable phenomenon that is consistent with both main-effect and stress-buffering models. Future work should focus on investigating this association in light of existing theories of depression.
\end{abstract}

Keywords: religion, spirituality, depression, mental health, meta-analysis. 


\section{Religiousness and Depression:}

Evidence for a Main Effect and

the Moderating Influence of Stressful Life Events

Depression and depressive symptoms are among the most common of all mental disorders and health complaints. Worldwide, as many as 330 million people may suffer from depression at any given time, with prevalence estimates ranging from 2-3\% for men and 5-12\% for women (American Psychiatric Association, 2000). Approximately 20 million visits to physicians in 1993-1994 involved reports of depressive symptoms (Pincus et al. 1998).

Depression is costly as well as prevalent: The worldwide market for antidepressants in 1998 was approximately $\$ 7$ billion (Editorial, 1998). In the United States alone, approximately $\$ 12$ billion in labor is lost to depressive symptoms each year. Moreover, depression is also a leading cause of physical disability and has even been found to be a risk factor for cardiovascular mortality (Saz \& Dewey, 2001; Wulsin, Vaillant, \& Wells, 1999).

Given the prevalence of depression and the burdens it creates, investigators have spent a great deal of effort trying to identify factors that may be useful for improving its detection and diagnosis. Well-established risk factors include (a) genetic factors (NIMH Genetics Working Group, 1998) (b) gender (Nolen-Hoeksema, Larson, \& Grayson, 1999); (c) social isolation (Barnett \& Gotlib, 1988; Joiner \& Coyne, 1999; Lara, Leader, \& Klein, 1997); (d) personality traits such as dependency, Introversion, and Neuroticism (Barnett \& Gotlib, 1988; Jorm, Christensen, Henderson, Jacomb, Korten, \& Rodgers, 2000), and (e) stressful life events (e.g., Nolen-Hoeksema \& Morrow, 1991; Monroe \& Simons, 1991).

Another variable that has recently received attention in the depression literature is religious involvement. Several recent high-profile studies (e.g., Braam et al., 2001; Koenig, 
George, \& Peterson, 1998; Murphy et al., 2000) indicate that certain aspects of religiousness (e.g., public religious involvement, intrinsic religious motivation) may be inversely related to depressive symptoms (with greater religious involvement associated with fewer symptoms of depression). Notably, Braam et al. (2001) reported that public religious involvement (viz., church attendance) was inversely related to depression among elderly individuals from European countries that were included in the EURODEP collaboration. Also Koenig et al. (1998) reported that among clinically depressed older adults, intrinsic religiousness was strongly associated with the speed with which their depressive episodes abated, even after controlling for a variety of potential confounds. Reviewers of the overall literature on religion and depression (e.g., Koenig, McCullough, \& Larson, 2001; McCullough \& Larson, 1999) have reached similar conclusions.

Studies on these issues have been accumulating for over 100 years (see McCullough \& Larson, 1999). Indeed, studies as far back as the 1880s have pointed to religion as a possible influence on the occurrence and severity of depression (Koenig et al., 2001). Given the perceived size and scope of this literature, scholars have recently recommended that investigators quantify and summarize this literature through meta-analysis so that the potential utility of religiousness as a predictor of depressive symptoms could be assessed more objectively (McCullough \& Larson, 1998), just as recent meta-analytic work has contributed to understanding of the nature of the relationship of religiousness and longevity (McCullough, Hoyt, Larson, Koenig, \& Thoresen, 2000). A similar meta-analysis on the relationship of religiousness and depressive symptoms also would permit an examination of several subsidiary questions.

\section{Possible Mechanisms of Association}

If religiousness and depressive symptoms are indeed related, what factors influence that relationship? It is challenging to offer a theoretical account that is both elegant and 
comprehensive because research has yet to confirm which variables moderate the relationship let alone which variables mediate it. Identification of moderating and mediating variables is important but difficult because both religiousness and depressive symptoms are influenced by a host of biological, social, and psychological factors. To complicate matters, the variables with which religion and depression are correlated typically are not exclusively one-way relationships: Because of the possibility of reciprocal relationships, many factors that are believed to be causes of depression may also be consequences of depression, and the same is true of religiousness. Regardless, insofar as a relationship between religiousness and depressive symptoms does exist, any of a variety of mechanisms might explain the association. Previous research suggests some possibilities that should inform future efforts, although not all of these possibilities can be addressed with meta-analytic methods at present.

Potentially Common Influences on Religiousness and Depressive Symptoms

Genetic influences. Religiousness might be associated with depressive symptoms due to similar genetic influences. Several studies suggest that $40 \%$ to $50 \%$ of the variance in religiousness may be attributable to additive genetic factors (Waller et al., 1990; D'Onofrio et al., 1999). To the extent that certain genes that confer resistance to depressive symptoms also contribute to the development of religious sentiments, one might expect a negative correlation between religious involvement and depressive symptoms. However, the multivariate behaviorgenetic studies that would shed light on this issue have not been conducted to date.

Developmental influences. Developmental factors that confer resistance to depressive symptoms may also foster the development of religious interests in children and adolescents. For example, warm and caring child-parent bonds may be both a protective factor against depression (Ingram \& Ritter, 2000) and a positive factor in development of religious interests (at least 
within religious families, Wilson \& Sherkat, 1994). Therefore, parental warmth, closeness, and caring may explain some of the association of religiousness and resistance to depressive symptoms. Conversely, negative life events during childhood that might confer risk for depressive symptoms might also disincline people from interests in or concerns with religious matters. Some research has indicated that poor relationships with parents may predispose an individual to depression and contribute to a lack of interest in religious matters (Hunsberger, 1980). It may also be that some individuals seek out religion to compensate for poor relationships with parents (Granqvist, 1998; Kirkpatrick \& Shaver, 1990).

\section{Depressive Influences on Religiousness}

In addition to the possibility that the associations between religiousness and depression are influenced by common developmental factors, there are good reasons to believe that depressive symptoms might influence religiousness. People who are experiencing high levels of depressive symptoms may find a lack of pleasure in former religious involvements, which might over time erode their public and even private engagements with their religious faith. Moreover, to the extent that a person's depressive symptoms include a lack of energy or a physical disability, previously religious people may find themselves unable to engage in religious pursuits, by extension making them seem less "religious" on many metrics for assessing religiousness. On the other hand, depressive symptoms apparently prompt some people to seek comfort in their religion (e.g., by attending religious services or reading holy scripture), which might, de facto, increase their apparent religiousness (Ferraro \& Kelley-Moore, 2000).

\section{Religious Influences on Depressive Symptoms}

Another possibility, that factors associated with religiousness influence symptoms of depression, has received the most attention in the recent empirical literature. Many researchers 
have suggested that religiousness may reduce vulnerability to depressive symptoms by way of a variety of substantive psychosocial mechanisms. Although an exhaustive list of these potential mechanisms is not feasible here, we illustrate with four possible mechanisms. (For a more extensive review see Koenig et al., 2001.)

Lower substance use. National surveys point to high rates of comorbidity between depressive symptoms and both drug abuse and drug dependence (Grant, 1995), which suggests that drug abuse/dependence may be risk factors for the development of depressive symptoms. Evidence also suggests that religious involvement is related to lower rates of substance use (e.g., tobacco, alcohol, and drugs) among both adolescents (D’Onofrio et al., 1999) and adults (Kendler, Gartner, \& Prescott, 1997). The effects of religion in deterring drug use may be largely through endorsing moral proscriptions and discouraging interaction with drug-using peers (D’Onofrio et al., 1999). Therefore, by deterring drug use among adolescents and adults, religious involvement might indirectly influence people’s susceptibility to depressive symptoms.

Social support. Religious involvement may afford people opportunities for social support, which has been found to protect against depressive symptoms (Koenig et al., 2001; George, Larson, Koenig, \& McCullough, 2000). People who are involved in religion have substantially more informal social contacts and are more active in civic engagements than people who are not (Putnam, 2000). Insofar as religious involvement puts people in touch with such sources of social support, this participation may be a mechanism that accounts for some of the inverse association of religiousness and depressive symptoms.

Appraisal of life events. Religiously involved people may have resources for appraising negative life events that reduce the perceived stressfulness of those events (Pargament, 1997). To the extent that religious people believe that their lives are controlled by a higher power or that 
negative life events happen for a reason, or that life events are opportunities for spiritual growth, they may experience life events as less threatening and less stressful (George et al., 2000). As a result, these positive appraisals may help to protect some religious individuals from depressive symptoms by helping them to perceive negative events as less stressful.

Coping with stress. Pargament (1997) also described how a variety of religious cognitions and behaviors that help religiously involved people to cope with stress may deter negative mental health outcomes. Relatedly, Koenig et al. (1992) reported that medically ill men who reported using religion to cope with their physical health problems also reported less severe depressive symptoms, even with a variety of other demographic, physical, and psychosocial predictors of depression controlled. Such findings suggest that religiousness may protect people against depressive symptoms by helping them to avert the negative psychological sequelae that are frequently associated with stressful life events.

\section{Main Effect or Stress-Buffering Effect?}

Insofar as religious involvement is inversely related to depressive symptoms, it is conceivable that this association applies equally to persons irrespective of the amount of life stress that they experience. This hypothesis has been called the main effect hypothesis, signifying that the association of religiousness and depressive symptoms is significant and negative when averaged across all levels of life stress. On the other hand, it is conceivable that, like many psychosocial factors that are related to depressive symptoms, the negative association of religious involvement and depression is even stronger for people who have recently undergone high amounts of life stress. This view has been called the buffering hypothesis (Cohen \& Wills, 1985). 
The main effect hypothesis and buffering hypothesis are not mutually exclusive, of course: It is possible for religious involvement to be related to significantly lower degrees of depressive symptoms for all persons and for the association to become even stronger for people who are undergoing particularly high levels of life stress. Indeed, some investigators have found evidence for both hypotheses (e.g., Kendler, Gardner, \& Prescott, 1999). Relatedly, it is conceivable that the negative association between religious involvement and depressive symptoms becomes particularly strong among people who are undergoing moderate or severe depressive difficulties. Depressive symptoms themselves can be a substantial source of life stress that may require secondary coping efforts for the individual to avoid being caught in a downward spiral. Theory development in the study of religion and mental health would benefit greatly from knowing whether the religious involvement-depressive symptoms relationship is consistent with the main effect hypothesis, the buffering hypothesis, or both (Schnittker, 2001).

\section{Other Potential Moderators of the Association}

Given reports of differences in the rates of religiousness and depression across sociodemographic groups (e.g., American Psychiatric Association, 2000; Levin, Taylor, \& Chatters, 1994; Nolen-Hoeksema et al., 1999; Taylor, Chatters, Jayakody, \& Levin, 1996), it is conceivable that the religiousness-depression association is not uniform across ethnicity, age, and gender. If so, the apparent disparities among some of the results that investigators have obtained may be caused by differences in the nature of the samples studied. For example, the religiousness-depression relationship may be stronger for women than for men, for older adults than for younger adults, or for African Americans than for European Americans (Blaine \& Crocker, 1995; Musick, Koenig, Hays, \& Cohen, 1998). 
Relatedly, it is likely that the methods used to measure religiousness and/or depression within these studies have a reliable impact on the strength of the associations (Schnittker, 2001). In a recent narrative review, McCullough and Larson (1999) noted that the negative association of religiousness and depressive symptoms appeared to be particularly strong when religiousness was measured in terms of public religious involvement or intrinsic religious motivation (Allport \& Ross, 1967), but less so when religiousness was measured in terms of private religiousness such as the strength with which people hold particular religious beliefs. Moreover, McCullough and Larson also noted that manifestations of religiousness that are extrinsically motivated, perhaps as a means to non-religious ends (Allport \& Ross, 1967), may actually be associated with a higher risk for depressive symptoms. The postulate that extrinsic religiousness is a maladaptive form of religiousness, predictive of negative outcomes such as mental illness as opposed to mental health, has been supported by others (e.g., Donahue, 1985; Richards \& Bergin, 1997).

These findings are conceptually similar to claims concerning negative forms of religious coping, such as blaming God for life’s problems or avoiding problems through religious activities, that may also predict mental illness as opposed to mental health (e.g., Pargament, 1997). Nevertheless, the purported association between religiousness and depression as well as the effects of different types of religiousness on that association observed in narrative reviews have yet to be confirmed using empirical methods for synthesizing scientific literatures.

We investigated issues raised above that were possible to address using extant data from the literature on religiousness and depressive symptoms. In this meta-analysis, our major goals were to (a) estimate the average magnitude of the association between measures of religiousness and depressive symptoms; (b) assess whether the association of religiousness and depressive 
symptoms is consistent with a main-effect model, a stress-buffering model, or both; and (c) identify characteristics of study samples and methods that might explain variation in the religiousness-depression association. In addition, we assessed the vulnerability of our conclusions to publication bias (Rosenthal, 1979; Sutton, Song, Gilbody, \& Abrams, 2000).

\section{Method}

\section{Literature Search}

To identify published and unpublished studies examining the association of religious involvement with symptoms of depression, we used three techniques. First, we conducted searches with several electronic databases: Cumulative Index to Nursing and Allied Health Literature (CINAHL), Dissertation Abstracts, Education Resources Information Center (ERIC) database, HealthSTAR, Medline, Mental Health Abstracts, Programme Appliqué à la Sélection et la Compilation Automatique de Littérature (PASCAL), PsycINFO, Religion Index, Social Sciences Abstracts, Social SciSearch, Sociological Abstracts via SocioFile, Social Work Abstracts, and TGG Health \& Wellness database. To capture the broadest possible sample of relevant articles, we used multiple search terms: all words beginning with the root depress, as well as terms such as affective disorder, mood, and affect. These search terms were crossed with a series of search words related to religion and religious spirituality (all words beginning relig, spirit, church, mosque, synagogue, temple, worship, and pray). To reduce inadvertent omissions, databases yielding the most citations (CINAHL, Dissertation Abstracts, Medline, PsychINFO, and Social Science Abstracts) were searched one to three additional times by different members of the research team. Second, we manually examined the reference sections of past reviews and of studies meeting the inclusion criteria for articles not identified in the database searches. Finally, we sent solicitation letters to authors who had published three or more articles on the 
topic to obtain several additional unpublished studies. Unpublished studies and dissertations obtained by contacting the authors or university libraries eventually accounted for $24 \%$ of included reports.

\section{Inclusion and Exclusion Criteria for Relevant Studies}

Studies included in the present investigation met the following criteria: First, they were written in English and were identified by searches conducted through February, 2000. Second, they provided an estimate of the bivariate association of religiousness and depressive symptoms at the level of an individual person (studies reporting group-level data on incidence rates were not included). Thus each study involved at least one measure of an individual's depressive symptoms and at least one measure of that same individual's religiousness.

Religiousness was defined broadly as any attitude, belief, motivation, pursuit, or behavior involving spiritual or religious content or processes. The terms religiousness and spirituality can both refer to an individual's search for that which is sacred, with the former implying group/social practices and doctrines and the latter tending to refer to personal experiences and beliefs. This meta-analysis uses the word religiousness because the majority of research studies reviewed used similar terminology and because religion encompasses pursuits and behaviors that are not necessarily spiritual (e.g., seeking social support from a congregation) (Hill et al., 2000). Because existing measures of religiousness and spirituality greatly overlap in content (Tsang \& McCullough, In press), studies that used either term were included in the analyses. Studies that reported only religious affiliation or spiritual group membership were excluded because membership status alone cannot be reliably inferred to represent an individual's beliefs, motivations and behaviors (e.g., Richards \& Bergin, 1997). 
We defined symptoms of depression more narrowly, only including studies with measures that explicitly used the term “depression” and that assessed a cluster of symptoms consonant with and specific to depressive disorder (American Psychiatric Association, 2000). Consistent with the view that depressive symptoms and depressive disorder reside on a single continuum (see also Hankin \& Abramson, 2001), studies were included that involved measures of depressive symptoms as well as those that diagnosed participants into "depressed" and "not depressed" categories based on psychiatric diagnoses or the use of cut-off scores. Studies that used only measures of global mental health or affect or measures specific to life satisfaction, loneliness, or suicidal ideation were excluded.

\section{Data Coding}

Coders received extensive training to increase the reliability of their efforts. To minimize the likelihood of rater bias, method sections were coded separately from the results (Owin, 1994; Sacks, Berrier, Reitman, Ancova-Berk, \& Chalmers, 1987). To decrease the likelihood of human error in coding data, teams of two raters reviewed each article. Team members helped one another to verify the accuracy of coding and data entry. Subsequently, each article was coded by a different team of two raters (57\%) or by the first author (43\%). The coders were advanced psychology students who coded the methods sections of the studies separately from the results sections.

Coders extracted several objectively verifiable characteristics of the studies: (a) the field of inquiry (psychology, medicine, etc.) and outlet (journal article, dissertation, etc.); (b) the number of participants and their composition by gender, ethnicity, age, and religious affiliation if reported; (c) the location of data collection if reported (nursing home, university class, etc.); (d) the design type (cross-sectional, longitudinal, experimental, quasi-experimental, and archival, 
with archival studies using data collected from extant records [archives] and not from recruited participants); and (e) the name of the measure(s) of religious involvement. Because most of the information listed above was extracted verbatim from the reports, inter-rater agreement was quite high for categorical variables (Cohen’s kappa ranged from .85 to .97 across variables, with an average value of .90) and for continuous variables (intraclass correlations [Shrout \& Fleiss, 1979] ranged from .65 to .99, with a mean of .89). After computation of inter-rater reliability coefficients inter-rater discrepancies were resolved by discussion and consensus.

Coders also made inferences regarding three variables, based on information in the reports: participants' average levels of stress, participants’ average levels of depression, and the aspect of religiousness measured in the study. The inferred average level of depression of the participants was coded as minimal, mild, or moderate. For each effect size involving a standard measure of depression, we determined the severity of depressive symptoms by comparing the mean depression score for the sample to published norms. When mean scores were not reported, coders examined the descriptions of the study samples. If no pertinent information was provided, the sample was coded as having minimal levels of depression. When descriptions of the sample yielded information suggesting a higher rate of depressive symptoms than in normal populations, the sample was coded as having a mild level of depression. Finally, if the descriptions indicated that participants had been diagnosed with major depression, the study was coded as having a moderate level of depression.

Similarly, the research participants’ average level of stress associated with life events was coded based on descriptions of sample characteristics. If the author(s) of the studies reported no unusual circumstances or sample characteristics, the study was coded as having minimal life event stress. Wherever any descriptions yielded pertinent information about the sample, these 
characteristics were compared with the ratings of perceived life event severity provided by Hobson et al. (1998), based on the original work by Holmes and Rahe (1967). The continuous ratings provided by Hobson and colleagues were trichotomized in such a way that people undergoing life events that were of similar severity to being the victim of a crime or going through a recent divorce were rated as undergoing "severe" life stress. People undergoing events similar to having major disagreements with an employer or being involved in an auto accident were characteristic of the bottom two-thirds of Hobson's scale. People undergoing such stressors were rated as experiencing "mild to moderate" life stress.

When the dimension of religiousness measured in a study was not explicitly stated, it was inferred by the coders. Each measure was assigned to one of seven categories, which were similar to those used by Hill and Hood (1999) in their comprehensive review: (1) Religious behaviors (measures of the frequency of saying prayers, participating in worship services, reading sacred texts, and/or performing religious service), (2) Religious attitudes/beliefs (measures of the perceived importance of religion, belief in deity, religious values), (3) Religious orientation (measures of the motivation for religious behaviors, intrinsic and extrinsic) (e.g., the Religious Orientation Scale [Allport \& Ross, 1967]), (4) Religious coping (measures of the use of positive and negative strategies for dealing with difficulties, such as seeking support from God vs. blaming God for the problem) (e.g., the Religious Coping Activities Scale [Pargament et al., 1990]), (5) Religious well-being (measures of life satisfaction in relation to religious beliefs, such as personal feelings of a connection with God) (e.g., the Religious Well-Being subscale of the Spiritual Well-Being Scale [Ellison, 1983]), (6) God concept (measures that assessed perceptions of the extent to which one holds a positive or negative image of God), and (7) 
Multidimensional aspects of religiousness (measures that included more than one of the above content areas).

In coding the three inferred variables, the two coding teams demonstrated adequate reliability (Cohen’s kappa for inferred depression $=.85$, for life stress $=.87$, and for type of religiousness $=.86$ ). As with other inferences and classifications, discrepancies were resolved by discussion and consensus.

\section{Computation of Effect Size Estimates}

The majority (76\%) of identified studies reported the association of religious involvement and depressive symptoms with the correlation coefficient. The data from other studies were transformed to correlation coefficients using the Meta-analysis Calculator software (Lyons, 1996). When no statistic was provided but an analysis was reported as significant, we determined the correlation coefficient corresponding to the reported alpha level (assuming two-tailed alpha $=$ .05 unless reported otherwise). When an analysis was reported as non-significant but no additional information was available, we set the correlation coefficient to $\underline{r}=.00$. These procedures yielded conservative effect size estimates. For the purposes of aggregation, correlation coefficients reported in individual studies were transformed into Fisher's stabilizing $\underline{z}$ scores (Shadish \& Haddock, 1994) to avoid the small amount of bias in Pearson’s $\underline{r}$ estimates. The resulting average across all studies was then converted back to the metric of a correlation. The direction of all effect sizes was coded uniformly, such that positive values indicated that religiousness was associated with greater symptoms of depression and negative values indicated that religiousness was associated with fewer symptoms of depression.

Several studies reported data on either multiple measures of religious involvement or multiple measures of depression. For example, some studies assessed attendance at religious 
services and frequency of personal prayer as well as aspects of religious belief or commitment. Use of each of these effect sizes in the omnibus analysis would have violated the assumption of independent samples (Cooper, 1998; Hedges \& Olkin, 1985). We therefore used the "shifting units of analysis” approach to analysis, which minimizes the threat of non-independence in the data while at the same time allowing more detailed follow-up analyses to be conducted (Cooper, 1998). Each single effect size estimate within each study was coded as if it were an independent event. However, in determining the overall association of religious involvement and depression, the effect sizes within each study were averaged so that each study contributed only one data point to the omnibus analysis (Mullen, 1989). This average effect size was used in subsequent analyses except where more detailed information was required. In such cases, the specific effect size representing the information needed was used in the analysis, rather than the average of all effect sizes extracted from the study.

Analyses

To aggregate effect sizes and to estimate the reliability of these aggregates, random effects models were calculated using Comprehensive Meta-Analysis software (Borenstein, 2000). A random effects approach yields results that generalize beyond the sample of studies actually reviewed (Hedges \& Vevea, 1998). The assumptions made in this meta-analysis clearly warrant this method: The belief that certain variables serve as moderators of the observed association between symptoms of depression and religious involvement implies that the studies reviewed will estimate different population effect sizes. Random effects models take such between-studies variation into account, whereas fixed effects models do not (Mosteller \& Colditz, 1996). 
Following the computation of the overall association of symptoms of depression to religious involvement, random effects weighted regression models and mixed effects analyses of variance (ANOVAs) were conducted using SPSS macros developed by Lipsey and Wilson (2001) to examine the influence of potential moderating variables. Such analyses are useful in determining circumstances under which the association between symptoms of depression and religious involvement varies in strength, such that a more accurate depiction of the association is provided. To correct for the number of analyses conducted, the level of statistical significance was set at $\underline{\mathrm{p}}<.0035$ in this study.

Results

\section{Descriptive Characteristics}

Effect sizes based on non-overlapping samples of participants were extracted from 147 studies. Table 1 provides an overview of descriptive information about these studies. Table 2 provides a description and the effect size estimate for each individual study. Across all studies, data were reported from a total of 98,975 participants. Participant gender was reported in 137 studies (93\%), with 61\% of the total participants being female. Participant ethnicity was reported in 95 studies (65\%), with a breakdown of 53\% European Americans, 24\% African Americans, 12\% Northern Europeans, 5\% Hispanic/Latino Americans, 1\% Asian Americans, 1\% other Americans (e.g., Native Americans), and 4\% participants from other nations (e.g., Australia, China, India). Religious affiliation was reported in 45 studies (31\%), with 49\% Protestants, 30\% Catholics, 17\% unspecified or unaffiliated, 3\% Jewish, and less than 1\% others (e.g., Muslim). Descriptions of participant characteristics resulted in 90 (61\%) studies being coded as having participants with minimal life event stress, 32 (22\%) having participants with mild to moderate stress, and 25 (17\%) having participants with severe stress. Mean scores on measures 
of depressive symptoms as well as descriptions of participant characteristics resulted in 104 (71\%) studies being coded as having participants with minimal symptoms of depression, 25 (17\%) studies having participants with mild symptoms, and 18 (12\%) studies having participants with moderate symptoms. Descriptions of instrumentation indicated that $35 \%$ of the studies used multidimensional measures of religiousness, $20 \%$ used measures of religious behaviors, $12 \%$ used measures of religious attitudes/beliefs, $15 \%$ used measures of religious orientation, $8 \%$ used measures of religious coping, 7\% used measures of religious well-being, and 3\% used measures of God concept.

\section{Omnibus Analysis}

As indicated previously, each study contributed only one data point in the omnibus analysis. Across all 147 studies the random effects weighted average effect size was $\underline{r}=-.094$ $(\underline{\mathrm{SE}}=.009, \underline{\mathrm{p}}<.000001,95 \%$ Confidence interval $=-.11,-.08)$. Of 140 nonzero effect sizes, 113 (81\%) were negative and 27 (19\%) were positive, with r’s ranging from -.54 to .24. The variability of effect sizes was quite high, and the index of heterogeneity was statistically significant, $\mathrm{Q}_{(146)}=814.0, \underline{\mathrm{p}}<.001$, suggesting that systematic effect size variability was unaccounted for. We therefore conducted additional analyses to determine the extent to which the variability in the magnitude of the effect size was moderated by other variables.

A visual display of the effect sizes (x-axis) by the number of participants per study (logarithmic y-axis) is presented in Figure 1. The scatterplot demonstrates a funnel-shaped pattern around the mean effect size, with the exception that extreme positive and extreme negative effect size estimates may have been underrepresented in studies with small sample sizes. Because studies with low sample size tend to remain unpublished, examination of potential publication bias was necessary (Rosenthal, 1979). 


\section{Assessment of Publication Bias}

Publication bias, sometimes called the "file drawer" effect (Rosenthal, 1979), is a tendency for studies on a given topic with large (and/or statistically significant) effect size estimates to have a higher likelihood of being published than do studies that yield smaller (and/or statistically non-significant) effect size estimates. Because published studies-which tend to possess strongest effect size estimates-are easier for meta-analysts to obtain than are unpublished studies, the effect size estimates resulting from a meta-analysis can be biased against the null hypothesis.

To examine the extent to which our results might be biased by the file drawer effect, we first compared the mean weighted effect size from unpublished reports to the mean weighted effect size from published reports. As seen in Table 3, studies that were published in journals (mean $\underline{r}=-.096$ ) yielded slightly larger effect sizes than did studies that were unpublished (viz., conference presentations, theses, and dissertations; mean $\underline{r}=-.087)$. A mixed effects ANOVA conducted between published and unpublished studies revealed no statistically significant difference $\left(\mathrm{Q}_{\mathrm{b}}=.15, \mathrm{p}=.70\right)$. Thus although we found that unpublished studies may yield slightly smaller estimates of the religiousness-depressive symptoms association than do published ones, the amount of bias appears to be trivial (i.e., less than 1 correlation point) and is statistically non-significant. Calculation of a fail-safe N (Begg, 1994) showed that 4,128 studies averaging an effect size of $r=.00$ would be required to render the present omnibus effect size estimate statistically non-significant.

Because of limitations of the fail-safe $\mathrm{N}$ and similar approaches, non-parametric methods based on the funnel plot distribution (Figure 1) have recently been developed to test and adjust for possible publication bias (Sutton et al., 2000). Duval and Tweedie (2000a, 2000b) describe 
the "trim and fill" method of estimating the number of missing studies due to publication bias and recalculating the weighted mean effect size accordingly. In an iterative process, outlying studies that have no corresponding values on the opposite side of the funnel plot distribution are temporarily removed ("trimmed"), and the mean effect size is recalculated, repeating the procedure until the distribution is symmetrical with respect to the mean. In our analyses, we followed the recommendations of Duval and Tweedie (2000b) in using $L_{0}{ }^{+}$to estimate the number of "missing” studies using formulae provided by Jennions and Moller (2002). The final step in the procedure is to replace the "trimmed" studies along with "filled" estimated values of the "missing" studies on the other side of the funnel plot distribution. The values for the "filled" studies are exactly opposite those "trimmed." The resulting data set inclusive of "filled" missing studies is then used to calculate a new omnibus effect size and its confidence intervals, with statistically non-significant values indicating potential publication bias. In the current study, the recalculated random effects weighted mean effect size was $\underline{r}=-.088(\underline{p}<.00001,95 \%$ Confidence interval $=-.10,-.07)$. Based on these analyses, publication bias seems an unlikely threat to the results presented here.

\section{Moderation By Sociodemographic Variables}

To examine whether the association of religiousness and depressive symptoms varied as a function of various sociodemographic variables, we conducted a series of categorical (and where appropriate, continuous) moderator analyses using the data from all 147 studies (see Table 3). The amount of between-studies variance that is accounted for by an individual moderator variable is indexed by the $\mathrm{Q}_{b}$ statistic. Statistically significant $\mathrm{Q}_{\mathrm{b}}$ values for an individual moderator variable indicate that the mean effect sizes differ across various levels of the 
moderator variable. The amount of remaining variance within studies is indexed by the $\mathrm{Q}_{\mathrm{w}}$ statistic, for which significant values indicate that the remaining variance is greater than zero.

To determine whether differences in the gender composition of the samples account for significant between-studies variance, we first correlated the percentage of females from the 137 studies that reported participant gender with the corresponding average effect size. This random effects weighted correlation was .001 $(\underline{p}=.98)$. We then analyzed effect sizes calculated with non-overlapping female only or male only samples. As can be seen in Table 3, this breakdown by gender did not account for substantial between-studies variation $\left(\mathrm{Q}_{\mathrm{b}}=.001, \mathrm{p}=.98\right)$. To hold other variations in method constant, we then compared effect sizes from 18 studies that reported data separately for both men and women. However, the differences observed between the estimates using female participants (mean $\underline{r}=-.134)$ and those using male participants (mean $\underline{r}=$ -.138) were not statistically significant $\left(\mathrm{Q}_{\mathrm{b}}=.009, \mathrm{p}=.93\right)$. Fewer than three studies reported data broken down across equivalent age groups, making it impossible to conduct more detailed analyses within studies. Nevertheless, the religiousness-depressive symptoms association does not appear to be moderated by gender.

To determine whether differences in the ethnic composition of the sample accounts for significant between-studies variance, we correlated the percentage of European Americans in the 95 studies that reported ethnicity with the corresponding average effect size. This random effects weighted correlation was $-.05(\mathrm{p}=.60)$. We then analyzed effect sizes calculated exclusively with samples of a specific ethnic group. These categorical analyses were only possible for contrasting the mean effect sizes for samples of African Americans, European Americans, and Northern Europeans because fewer than three articles reported data specific to any other ethnic group. As may be seen in Table 3, this ethnic breakdown did not account for significant between- 
studies variation in effect sizes, $\mathrm{Q}_{\mathrm{b}}=.51, \mathrm{p}=.78$. To hold other variations in method constant, we then compared effect sizes from six studies that reported data separately for African American and European American participants (no other ethnic groups were represented by separate data within studies). The differences observed between the estimates using African American participants (mean $\underline{r}=-.132$ ) and those using European American participants (mean $\underline{r}$ $=-.114)$ were not statistically significant $\left(\mathrm{Q}_{\mathrm{b}}=.024, \mathrm{p}=.88\right)$. Thus the relationship between religiousness and depressive symptoms does not appear to be moderated by ethnicity.

To investigate the potential effect of participant age upon the relationship between religiousness and depressive symptoms, we conducted a random effects weighted correlation with the mean age of the sample and the effect size of the study, with the resulting coefficient being -.19 $(\mathrm{p}=.007)$. To further explore this relationship, we broke down participants' average age into eight categories. As can be seen in Table 3, the magnitude of the association of religiousness and depressive symptoms was highest at retirement age. Nevertheless, the mixed effects ANOVA conducted between the age groups failed to reach the $\underline{p}<.0035$ level of statistical significance $\left(\mathrm{Q}_{\mathrm{b}}=18.9, \underline{\mathrm{p}}=.009\right)$. Therefore, the association of religiousness and depressive symptoms does not appear to be moderated by age.

\section{Main Effect vs. Stress-Buffering Effects}

If religiousness buffers people against the effects that stressful life events can have on depression, then the association of religiousness and depression should be stronger at high levels of stress than at low levels of stress (Cohen \& Wills, 1985). If religiousness exerts a main effect on depression, then the association of religiousness and depressive symptoms should be significant at all levels of life stress. Of course, if both the buffering model and the main effect model are accurate, then both sets of conditions may hold. We evaluated both hypotheses by 
inspecting the differences in mean effect sizes obtained from samples with differing degrees of life events stress and with differing degrees of depressive symptoms (which themselves are a source of significant life stress).

The inferred amount of life event stress attributed to each sample accounted for substantial between-studies variation $\left(\mathrm{Q}_{\mathrm{b}}=15.9, \mathrm{p}=.0004\right)$. The religiousness-depressive symptoms association for people with minimal life stress (mean $\underline{r}=-.071$ ) was smaller in magnitude than was the association for people with mild to moderate (mean $\underline{r}=-.141$ ) or severe life stress (mean $\underline{r}=-.152$ ). The random effects weighted correlation between rated life stress and mean effect size was -.26 , which was statistically significant $(\underline{p}=.0001)$. Thus, higher rated life stress was associated with stronger negative correlation of religiousness and depressive symptoms. These results suggest that the negative association of religiousness and depressive symptoms is at its strongest when people are undergoing stressful life events, which is consistent with the buffering hypothesis. However, at all levels of inferred life stress the association of religiousness and depressive symptoms is significant and negative, which is also consistent with the main effect hypothesis. Thus our results provide support for both models of the religiousnessdepressive symptoms association.

The degree of depressive symptoms attributed to each sample was also investigated. The association among studies in which the mean level of depression was "minimal" (mean $\underline{r}=-.078$ ) was smaller in magnitude than for samples that were judged as having a "mild" (mean $\underline{\mathrm{r}}=-.135$ ) or "moderate” (mean $\underline{r}=-.151$ ) degree of depressive symptoms, but these differences were not statistically significant $\left(\mathrm{Q}_{\mathrm{b}}=10.0, \mathrm{p}=.007\right)$ by the stringent criterion that we adopted for statistical significance $(\mathrm{p}<.0035)$. Thus the rated level of depression did not moderate the association between religiousness and symptoms of depression. 
Insufficient numbers of studies reported data for non-overlapping samples with differing levels of stress and/or with differing levels of depression. We were therefore unable to perform additional analyses to confirm these findings within studies. However, as an additional step complimentary to the above analyses, we provide here a narrative summary of the findings from the studies that explicitly assessed the influence of level of depression and distress on the religiousness-depression association.

Only one study was identified that specifically assessed the religiousness-depression association across different levels of depression. In a survey of elderly adults, Klass (1998) found that the correlation between religiousness and symptoms of depression was -.29 among participants who were depressed compared to -.07 among participants who were not depressed.

Eight studies were identified that assessed the religiousness-depression association as a function of life stress. In a survey of bereaved parents, Maton (1989) reported that the correlation between religiousness and depression was $\underline{r}=-.33$ among participants who had experienced the recent death of a child (a group identified as experiencing high distress) compared to $\underline{\mathrm{r}}=-.16$ among parents who had lost a child more than two years previously (a group identified as experiencing lower levels of distress). Similarly, Robinson and Kaye (1994) found a correlation of -.21 between religiousness and depressive symptoms in a sample of caregivers of dementia patients compared to a correlation of +.05 among a sample of partners of healthy adults. Bickel et al. (1998) divided participants into high and low stress groups based on scores from a measure of perceived stress and found that correlations among high stress participants averaged -.27 while correlations among low stress participants averaged 0. In two separate studies, Park, Cohen, and Herb (1990) found interactions between religiousness and life stress in the prediction of depression, with religious coping buffering Catholics’ depression at high levels of controllable 
life stress and with intrinsic religious orientation buffering Protestants’ depression at high levels of uncontrollable life stress. Kendler, Gardner, and Prescott (1997) also found that religious devotion buffered the relationship between recent stressful life events and depression. Similarly, Hettler and Cohen (1998) reported a significant interaction effect between intrinsic religiousness and the number of negative life events in predicting symptoms of depression eight months later, with the positive relationship between negative life events and depression being weaker at higher levels of intrinsic religiousness compared to moderate and low levels of intrinsic religiousness. However, although Strawbridge, Shema, Cohen, Roberts, and Kaplan (1998) reported that both organizational and non-organizational religiousness buffered non-family stress (medical problems, financial problems, etc.), which finding replicated those reported above, they also found that in the presence of family distress organizational religiousness (but not nonorganizational religiousness) was positively correlated with depression - the opposite direction of their other results and the results of the studies cited previously. Similarly, although Belavich (1995) reported that religious coping activities predicted adjustment to daily hassles and stressful life events when controlling for nonreligious coping, there were no interaction effects between the number of daily hassles and religious coping when predicting depression. Finally, when dividing participants into three categories of church attendance (weekly, less often, and never), Thearle, Vance, Najman, Embeldon, and Foster (1995) found little difference in the magnitude of the religiousness-depression association among bereaved parents $(\underline{\mathrm{r}}=-.10)$ compared to a control group $(\underline{r}=-.08)$. By way of summary for this section, of the eight studies that reported data useful in testing the stress buffering hypothesis, five reported results supportive of the hypothesis, one reported mixed results, and two reported results that were not statistically significant. Thus the findings of individual studies tended to support the meta-analytic results 
that indicate a moderation effect of inferred level of distress upon the religiousness-depression association.

Moderation by Type of Measure of Religiousness

Another moderator analysis involved examining whether the association of religiousness and depressive symptoms differed as a function of how religiousness was measured, per the observations of McCullough and Larson (1999). A mixed effects ANOVA conducted across the nine types of measures reached statistical significance $\left(\mathrm{Q}_{\mathrm{b}}=170.5, \mathrm{p}<.0001\right)$. As may be seen in Table 3, studies that used measures of extrinsic religious orientation (mean $\underline{r}=.155$ ) or of negative religious coping (mean $\underline{r}=.136$ ) both tended to report positive associations between religiousness and depressive symptoms, whereas studies using all other measures yielded statistically significant negative associations. Post hoc analyses indicated that the effect sizes from studies using each of these two measures differed significantly from studies using any of the other measures $(\mathrm{p}<.0001)$. Post hoc analyses also revealed statistically significant differences between studies using measures of intrinsic religious orientation $(\underline{r}=-.175)$ and studies using measures of religious attitudes/beliefs $(\underline{\mathrm{r}}=-.053)\left(\mathrm{Q}_{\mathrm{b}}=8.7, \underline{\mathrm{p}}=.003\right)$. All other comparisons did not reach the $\underline{\mathrm{p}}<.0035$ level of statistical significance. Regression Model Predicting Effect Size from Potential Moderator Variables

To determine the degree of redundancy among the several predictors assessed in this study, we performed a random intercept, fixed slopes multiple regression model. Specifically, effect sizes were regressed on the demographic variables of participant gender composition, ethnicity (percentage of European American participants), and mean age, on the levels of rated life events stress and depression, and on the type of religiousness measured. Values for continuous moderator variables (e.g., gender composition, percentage of European American 
participants, age, stress, and severity of depressive symptoms) were centered on the betweenstudy means. Thus a value of zero, for example, for mean age, actually represented the average mean age across the population of studies included in the meta-analysis. The categories of measures of religiousness were dummy coded, such that each measure was contrasted with all other measures and such that the category "multidimensional measures” would fall in the 0, or other, category for each dummy variable.

The set of moderator variables accounted for $42.4 \%$ of the variance in effect sizes, which was statistically significant $\left(\mathrm{Q}_{13}=163.8, \underline{\mathrm{p}}<.0001\right)$. However, substantial between-studies variance remained unaccounted for $\left(\mathrm{Q}_{164}=222.2, \mathrm{p}=.002\right)$. Table 4 shows the regression coefficients and associated levels of statistical significance for each variable. The parameter labeled "Constant" is the effect size $(r=-.094, \mathrm{p}<.0001)$ that would be expected in a study in which all moderator variables took the value of zero. Interpretation of the B weights reveals the extent to which each study characteristic would be expected to influence the observed overall effect size when controlling for the presence of the other variables. Measures of extrinsic religiousness ( $\square=.239$ ) and negative religious coping ( $\square=.23$ ) were the only statistically significant predictors $(\mathrm{p}<.0001)$. Thus when studies use measures of extrinsic religiousness, the expected effect size would be $.145(-.094+.239)$, and when studies use measures of negative religious coping, the expected effect size would be .136 $(-.094+.230)$.

\section{Discussion}

In the present meta-analysis, we found evidence that religiousness is modestly but reliably associated with depressive symptoms at the bivariate level. This conclusion is robust and appears to apply across different gender, ethnic, and age groups. Thus our results largely support 
those of previous investigators who used narrative methods to review more limited selections of this literature (Koenig et al., 2001; McCullough \& Larson, 1999).

The omnibus effect size for this association was estimated at $\underline{r}=-.096$, suggesting that, on average, measures of positive religiousness account for about $1 \%$ of the variance in the severity of depressive symptoms in the population. Associations of this size are typically considered "small" (Cohen, 1987). By comparison, other meta-analyses have found that variables such as self-focused attention (Mor \& Winquist, 2002) and immunological parameters (Zorilla et al., 2001) on average correlate with depression in the absolute value range of .20 to .25. Thus, by statistical convention and in comparison to other predictors of depressive symptoms, religiousness appears to make a modest contribution to the prediction of depressive symptoms. Nevertheless, a small correlation need not be dismissed as trivial. For example, one might consider that the association between gender and depressive symptoms (i.e., women tend to have more severe depressive symptoms than do men) is similarly about $\underline{r}=.10$ (e.g., see NolenHoeksema et al., 1999, Table 1; Twenge \& Nolen-Hoeksema, 2001). Although the gender difference in depressive symptoms is "small" from a statistical perspective (and though it belies a large gender difference in the odds of depressive disorders; see Culbertson, 1997), it is reliable and has considerable scientific and social importance. Moreover, the gender difference in depressive symptoms has led to theoretical advances regarding the nature of depression itself (e.g., Nolen-Hoeksema, 1987; Nolen-Hoeksema et al., 1999). With the gender differences in depressive symptoms as a benchmark for how "small” associations can be important (see also Prentice \& Miller, 1992; Rosenthal, 1990), we also would suspect that despite the modest statistical strength of the association between depressive symptoms and religiousness, this association may have important implications for research and theory. 
The Roles of Gender, Ethnicity, and Age

In the present work we evaluated several subsidiary hypotheses regarding the association of religiousness and depressive symptoms. First, we evaluated whether the association was moderated by gender, ethnicity, or age. This hypothesis merited consideration in light of the demographic influences on religiousness (e.g., Levin et al., 1994) in conjunction with the consistent gender differences in depressive symptoms (Nolen-Hoeksema et al., 1999).

Our analyses indicated that the association of religiousness and depressive symptoms is substantial across age groups, genders, and the three ethnic groups for whom we could reliably estimate mean effect sizes (African Americans, European Americans, and Northern Europeans). Nevertheless, we did not find evidence that age, gender, or ethnicity moderates the association between religiousness and depression.

The Measurement of Religiousness

A major finding of this study is that the association between religiousness and depression significantly differs across the type of religiousness measured. Specifically, measures of extrinsic religious orientation, which assess the extent to which people involve themselves in religion for self-seeking ends (Allport \& Ross, 1967), and measures of negative religious coping, which assess the extent to which people cope with stress by making malevolent religious appraisals or engaging in counterproductive religious behaviors (Pargament, Smith, Koenig, \& Perez, 1998), showed different associations with measures of depressive symptoms than did all other measures of religiousness. In fact, whereas one would expect most measures of religiousness to have a negative association with depressive symptoms, measures of extrinsic religious motivation and negative religious coping would be expected to have a significant and positive association with depressive symptoms. The clear contrasts found here between intrinsic vs. extrinsic religious 
motivation and positive vs. negative religious coping (see Measures of Religiousness in Table 3) give emphasis to the conclusions of others (e.g., Bergin, 1983; Burris, 1994; Donahue, 1985; Pargament, 1997; Richards \& Bergin, 1997) and strongly suggest that researchers should attend to individuals’ specific forms of religious motivation and coping.

However, the current trend in the research literature is to explore predominantly positive aspects of religiousness (e.g., assessments of the extent to which a person is engaged with his or her religious faith in a constructive, affectively positive, and intrinsically motivated way). For example, well over 100 measures of religiousness have been published in the professional literature, with the vast majority of these assessing only positive aspects of religiousness (Hill \& Hood, 1999). Scholars have long believed that some forms of religiousness are unhealthy (e.g., Bergin, 1983)—over 100 years ago James (1902) distinguished religiousness as "healthy mindedness" versus the "sick soul”-yet research efforts on the negative forms of religiousness have been notably limited. In this meta-analysis, only 31 (21\%) of the studies assessed either extrinsic religious motivations or negative religious coping. Clearly, researchers should give increased emphasis to the negative forms of religiousness, particularly when investigating debilitating conditions such as depression (Pargament, Koenig, \& Perez, 2000; Pargament, Zinnbauer, et al., 1998).

A related finding concerning the measurement of religiousness is that this study only found one statistically significant difference between the several categories of measures of positive religiousness: studies with measures of intrinsic religiousness had stronger negative correlations with symptoms of depression than studies with measures of religious attitudes/beliefs. The differences in the average effect sizes for other contrasts between measures of religious behavior (e.g., prayer, service attendance), religious attitudes (e.g., feelings about 
one's religion, belief in God), intrinsic religious orientation (e.g., motivation to be religious for its own sake), religious well-being (e.g., positive emotions associated with religious worship), and God concept (e.g., perceptions of a benevolent deity) did not reach the criterion for statistical significance to which we adhered $(\underline{\mathrm{p}}<$.0035). These types of measures purportedly differ in the constructs they measure, with some authors advocating some aspects of religiousness over others. However, a difficulty that complicates efforts to determine superiority of some aspects of positive religiousness over others in terms of their value for predicting depressive symptoms is the fact that measures of positive aspects of religiousness typically are highly intercorrelated. It is common to find that measures_especially multi-item measures—ostensibly assessing distinct religious constructs are correlated on the order of $\underline{r}=.70$ to .80 (e.g., McCullough, Worthington, Maxey, \& Rachal, 1997). As a result, even though scholars might make fine-grained distinctions among religious constructs (for a comprehensive review see Hill \& Hood, 1999), the measurement tools that are typically used to operationalize these constructs are imprecise either (a) because they do not possess adequate discriminant validity, or (b) because the constructs assess a higher-order dimension of religiousness to such a degree that the measures are more or less substitutable (see Tsang \& McCullough, in press). Therefore, from the standpoint of attempting to designate clinically useful measures of positive religiousness, our findings suggest that with the exception of intrinsic religious orientation vs. religious attitudes/beliefs, the measures of the above-mentioned constructs do not differ in their ability to predict depressive symptoms.

\section{Stress Buffering Effects}

Some investigators (e.g., Kendler et al., 1999; Schnittker, 2001) have found evidence not only that religiousness is related to lower levels of depressive symptoms in general, but also that 
the association between religiousness and depression may be stronger at higher levels of psychosocial stress-a phenomenon called the buffering effect (Cohen \& Wills, 1985). We were able to explore this issue using meta-analytic methods in the present study. We found evidence supporting both the main effect model and the stress-buffering model of the religiousnessdepression association. Although religiousness was related to less severe depressive symptoms at all levels of life stress, their association was notably stronger in study samples that were inferred to be undergoing psychosocial stress. Examination of the results of eight studies that reported data with the potential to test the stress buffering hypothesis also appeared to support this finding.

Our confirmation that the existing empirical data are consistent with both a main effect hypothesis and a buffering hypothesis provides a foundation for further theoretical work on this topic. In particular, it would be useful not only to understand how religion is associated with protection from depressive symptoms among people undergoing daily lives with normal amounts of stress, but also to understand how religion is deployed by people under high levels of stress to reduce depressive symptoms. Several mechanisms might be relevant, including possible combinations of common influences upon depression and religiousness, influences of depressive symptoms upon religiousness, and influences of differential religiousness upon depression as a function of level of distress.

Potential Causal Accounts for the Religion-Depression Association

Our results suggest the presence of a small but robust negative association between religiousness and depressive symptoms, but gave only the faintest hint to the possible explanations underlying this negative association. Elucidating these mechanisms is certainly one of the most important priorities for future research on religiousness and depressive symptoms. 
Presently, we revisit three possible classes of causal mechanisms that could be evaluated in future work.

Could religiousness and vulnerability to depression be caused by common factors? A first class of possible explanations involve developmental factors (viz., genetic and environmental influences) that might influence both religiousness and vulnerability to depressive symptoms. Given the apparent heritability of religiousness (e.g., D’Onofrio et al., 1999; Waller et al., 1990), as well as the vulnerability to depressive symptoms, it is possible that common genetic factors are responsible for the association of religiousness and depressive symptoms. Similarly, environmental influences such as parental disciplinary styles, parental modeling of social skills and emotional management, and parent-child attachment styles could provide simultaneous influences on the development of religiousness, vulnerability to depressive symptoms, and effective coping with stress. For example, individuals who have experienced abusive or neglectful parenting may be more likely to experience depression, less likely to trust uncertain (e.g., unseen) sources of potential aid such as those offered in religious teachings, and also less likely to handle negative life events effectively compared to individuals who experienced other parenting styles, with the religiousness-depression association thereby increasing in magnitude under stressful conditions. These multiple influences as well as possible combinations between genetic and environmental factors are of course complex, but could be addressed in multivariate behavior-genetic studies and longitudinal studies with samples that were followed through important periods of psychosocial development (including, ideally, childhood and adolescence).

Other "third variables" merit further attention as well. For example, the possibility that the religiousness-depression association can be explained in terms of socially desirable 
responding — which might make people prone both to exaggerated reports of some forms of religiousness, as well as reduced reports of depressive symptoms—should be considered. Although the correlations of measures of religiousness and of social desirability are probably quite small (Trimble, 1997), the small size of religiousness-depression association suggests that the possible role of such response artifacts should be given explicit attention.

Could depression reduce religiousness? Investigators should also consider the possibility that depressive symptoms affect religiousness. A loss of interest in previously pleasurable activities and a loss of energy are common symptoms of depression (American Psychiatric Association, 2000). Insofar as religiousness is valued by an individual, becoming depressed should lead to reductions in his or her religious interests and religious behaviors. Moreover, during times of distress, individuals who already display some symptoms of depression tend to show an increase in the number of symptoms manifested (Nolen-Hoeksema \& Morrow, 1991). In such cases, individuals would likely appear less religious than they would otherwise because the exacerbated symptoms of depression might lead to a withdrawal from religious activities. Longitudinal studies that closely track participants' religiousness and depressive symptoms relative to the occurrence of negative life events would help to disentangle this possibility from the opposite explanation that during times of distress, some individuals are apparently prompted to seek comfort in their religion as a response to increased symptoms of depression (Ferraro \& Kelley-Moore, 2000; Idler, 1995). Of course, both influences could operate simultaneously or one influence could operate for some people, but not in others.

Could religiousness reduce depressive symptoms? Many possible mechanisms could explain how religiousness exerts a causal effect on depressive symptoms. For example, as discussed previously, highly religious individuals are less likely to abuse substances than 
individuals with marginal or low levels of religiousness (D’Onofrio et al., 1999; Kendler et al., 1997). Therefore, a possible partial explanation for the results obtained here that support the stress-buffering hypothesis is that individuals with moderate or low levels of religiousness may tend to engage in substance use during times of distress, with corresponding increases in reports of depressive symptoms (Grant, 1995), whereas highly religious individuals may remain comparatively low in their use of psychoactive substances even under stressful conditions (e.g., by invoking other coping resources besides substance abuse).

Moreover, the social support that often is associated with involvement in a local religious congregation—long known to be a buffer against the negative effects of stress (George et al., 2000; Koenig et al., 2001; Levin, 2001)—could explain how religiousness reduces depressive symptoms. Compared to their less religious counterparts, highly religious individuals are more likely to be married and have stable family relationships (e.g., Mahoney, Pargament, \& Tarakeshwar, 2001) and overall more likely to have relationships of high quality (e.g., Chang, Noonan, \& Tennstedt, 1998). At high levels of distress, individuals who have social support will be able draw upon those resources for assistance, whereas individuals who do not have adequate social support are prone to develop depressive symptoms (Barnett \& Gotlib, 1988; Joiner \& Coyne, 1999; Lara et al., 1997).

Religious differences in how people both perceive and cope with stressful life events implies another set of possible mechanisms of association merit more research. Existing research indicates that religiously committed individuals have relatively hopeful and positive outcome expectancies (Fehring, Miller, \& Shaw, 1997; Sethi \& Seligman, 1993), which might afford them additional strength and comfort in the face of life difficulties. Specific religious beliefs may also facilitate interpreting and managing specific types of negative life events. For example, under 
conditions of severe physical illness, religious beliefs about finding meaning in suffering may help normalize experiences of pain (Steinfeld, 1999) and religious beliefs concerning an afterlife may reduce medical patients’ fear of death (Alvarado, 1995).

Relatedly, the apparent buffering effect noted in this study may be partially attributable to difference in coping strategies used for people with differing degrees of religiousness. For example, highly religious individuals may be more likely to express their emotions openly than do others (Meador et al., 1992). Because emotional expression can facilitate coping with distress (Kennedy-Moore \& Watson, 2001) highly religious individuals would be more likely to benefit accordingly, increasing the magnitude of the religiousness-depression association. Similarly, messages of altruistic service that are common to most world religions may assist highly religious individuals to focus on the needs and problems of other people during their own periods of crisis and thus reduce the self-focused attention that characterizes depression and other clinical disorders (Ingram, 1990; Mor \& Winquist, 2002). Messages supportive of accepting one’s fate that are characteristic of many Eastern religions (Richards \& Bergin, 2000) or messages of forgiveness (e.g., Coates, 1996) and grace (e.g., Watson, Morris, \& Hood, 1989) that are particularly characteristic of the Abrahamic religions could have similar effects within religious groups.

\section{Exploring the Religiousness-Depression Association Further Will Require Greater}

\section{Methodological Diversity}

Nearly all of the studies of religiousness and depressive symptoms to date have been cross-sectional, non-experimental studies of unrelated individuals in which both religiousness and depressive symptoms were assessed via self-report. These studies have been useful for helping us conclude that the association of depression and religiousness is a reliable one, but 
studies employing such designs will be of very limited utility in shedding light on the causal mechanisms that underlie the religiousness-depression association. Obviously, to study genetic explanations, behavior-genetic studies will be necessary. To study developmental explanations, longitudinal studies_-including studies with very long follow-up periods—will be invaluable. And of course, to maximize our certainty about whether any particular causal account is valid, laboratory studies and randomized clinical trials that involve the manipulation of religious variables and/or depressive symptoms will eventually be necessary (and we think, under certain circumstances, will be both ethically and practically feasible).

Relatedly, it would be most helpful if our notions about causality were broadened from a strictly between-persons approach to a within-persons approach. Correlational studies showing that people who have high levels of religiousness cross-sectionally tend to have slightly lower levels of depressive symptoms have been valuable up to the present, but the field is, we think, approaching the point at which the knowledge that such studies can yield is quite small. By contrast, it would be extremely useful to know whether an individual who suddenly becomes depressed will also become less religious than is typical for him or her, and vice versa. This latter possibility implies that a cause-and-effect mechanism operates not only between persons, but within persons as well, and that both religiousness and depression are not fixed characteristics of persons, but changeable quantities that fluctuate over time, perhaps in a causal way. A host of research methods for examining within-person notions of causality are now at researchers’ disposal (e.g., Nezlek, 2001), and are perfectly suited for shedding light on questions of causeand-effect within individuals. We recommend strongly that investigators explore such approaches in future work.

\section{Limitations}


Having stated some directions in which further exploration of the religiousnessdepression association are likely to be fruitful, it is worthwhile to make explicit some of the limitations of the present work. First, the studies included in this meta-analysis were all written in English and used predominantly cross-sectional designs with mostly North American participants, the majority of whom were Christian. The results therefore may not generalize to other settings or groups. Second, the bivariate associations reported in individual studies do not account for possible curvilinear associations in the data, such as when individuals with high and low religiousness score similarly to one another but differently from moderately religious individuals (e.g,. Schnittker, 2001). Third, as noted earlier, it is possible that the religiousnessdepression association observed here could be attributable to a consistent response bias across participants and across studies, such as a desire to respond in socially appropriate ways, which could slightly elevate endorsement of religious items and slightly decrease reports of depressive symptoms. Third, is also possible that when participants complete measures of mental health at the same time as a measure of religiousness that their perception of their physical and mental health will tend to overlap with their perception of spiritual/religious well-being (Idler, 1995). Factors such as these can be assessed in future studies that do not rely so heavily upon data from self-report instruments.

\section{Conclusion}

The present project yielded evidence that religiousness is a robust correlate of depressive symptoms, albeit a modest one. These findings may present interesting opportunities for advancing knowledge regarding depression and depressive symptoms. In preparing the present meta-analysis, we were struck by how much of the empirical work on religiousness and depression has been conducted without much regard to the major psychological, sociological, or 
biological theories of depression. Researchers frequently alluded to possible mechanisms underling the religiousness-depression relationship (e.g., that religiousness provides hope, social support, or a coherent worldview that allows for more adaptive attributions during life stressors; George et al., 2000). However, for the most part the existing studies did not seem motivated by the desire to test specific hypotheses that emerge directly from well-articulated theories of depression. More often than not, researchers seemed motivated simply to ask, "Are depression and religiousness related?" or at best "What social or psychological factors moderate the religiousness-depression relationship?” with little apparent interest in using such hypothesis tests to evaluate the abilities of existing theories of depression to explain new depression-related phenomena.

This is not a cause for alarm; such gaps between theory and research are no doubt typical in new research areas. Until a new phenomenon is supported by a critical mass of observations supporting its validity and is acknowledged widely as being “real,” investigators probably focus largely on exploring whether the phenomenon exists at all rather than on testing theories for why it exists. To wit, theories of depression apparently had been inadequate to handle the gender difference in depression very well until it was confirmed that such a phenomenon actually exists and thus merits sustained theoretical attention. However, once the phenomenon was clearly established, theory began to advance admirably, making the way for informative research on the topic (e.g., Nolen-Hoeksema, 1987; Nolen-Hoeksema et al., 1999).

We believe the present meta-analysis similarly establishes the religiousness-depression relationship as a reliable phenomenon that merits sustained theoretical attention. We have offered some possible causal hypotheses that could account for the religiousness-depression association, and have made some methodological recommendations for the types of studies that 
would move our understanding forward substantially. Hopefully, with some reasonable assurance that the religiousness-depression association is "real," investigators who are interested in psychopathology, religion, or both can now feel confident about moving to the next generation of studies that will help us to understand the psychological and social processes that give rise to this modest but robust association—studies that are theoretically grounded, methodologically diverse, and focused on illuminating mechanisms of causality. 


\section{References}

References marked with an asterisk indicate studies included in the meta-analysis.

Allport, G. W., \& Ross, J. M. (1967). Personal religious orientation and prejudice. Journal of Personality and Social Psychology, 5, 432-443.

Alvarado, K.A. (1995). The relationship of religious variables to death depression and death anxiety. Journal of Clinical Psychology, 51, 202-204.

American Psychiatric Association (2000). Diagnostic and statistical manual of mental disorders ( $4^{\text {th }}$ edition, text revision). Washington, D.C.: Author.

*Austin, D., \& Lennings, C. J. (1993). Grief and Religious Belief: Does belief moderate depression? Death Studies, 17, 487-496.

*Baird, J. (1990). The relationship between suicide risk, hopelessness, depression, and religious commitment in high school students. Unpublished doctoral dissertation, California School of Professional Psychology, Fresno.

Barnett, P. A., \& Gotlib, I. H. (1988). Psychosocial functioning and depression: Distinguishing among antecedents, concomitants, and consequences. Psychological Bulletin, 104, 97126.

Begg, C. B. (1994). Publication bias. In H. Cooper and L. V. Hedges (Eds.) The handbook of research synthesis (pp. 399-409). New York: Russell Sage Foundation.

*Bekaroglu, M., Uluutku, N., Tariover, S., \& Kirpinar, I. (1991). Depression in an elderly population in Turkey. Acta Psychiatrica Scandinavica, 84, 174-178.

*Belavich, T. G. (1995, August). The role of religion in coping with daily hassles. Paper presented at the $103^{\text {rd }}$ Annual Convention of the American Psychological Association, New York, NY. 
Bergin, A. E. (1983). Religiosity and mental health: A critical reevaluation and meta-analysis. Professional Psychology: Research and Practice, 14, 170-184.

*Bergin, A. E., Masters, K. S., \& Richards, P. S. (1987). Religiousness and Mental Health Reconsidered: A study of an intrinsically religious sample. Journal of Counseling Psychology, 34, 197-204.

*Bickel, C. O., Ciarrocchi, J. W., Sheers, N. J., Estadt, B. K., Powell, D. A., \& Pargament, K. I. (1998). Perceived stress, religious coping styles, and depressive affect. Journal of Psychology and Christianity, 17, 33-42.

*Bienenfeld, D., Koenig, H.G., Larson, D. B., \& Sherrill, K. A. (1997). Psychosocial predictors of mental health in a population of elderly women. The American Journal of Geriatric Psychiatry, 5, 43-53.

*Biggar, H., Forehand, R., Devine, D., Brody, G., Armistead, L., Morse, E., \& Simon, P. (1999). Women who are HIV infected: The role of religious activity in psychosocial adjustment. AIDS Care, 11, 195-199.

*Bishop, L. C. (1987). Religious life of individuals with affective disorders. Southern Medical Journal, 80, 1083-1086.

*Blaine, B., \& Crocker, J. (1995). Religiousness, race, and psychological well-being: Exploring social psychological mediators. Personality and Social Psychology Bulletin, 21, 10311041.

*Blumel, S. R. (1993). Toward an understanding of depression in a religious, married population. Unpublished doctoral dissertation, Brigham Young University, Provo, Utah. *Bohrnstedt, G.W., Borgatta, E.F., \& Evans, R.R. (1968). Religious Affiliation, Religiosity, and MMPI Scores. Journal for the Scientific Study of Religion, 255-258. 
Borenstein, M. (2000). Comprehensive meta-analysis [Computer software]. Englewood, NJ: Biostat.

*Bozarth, M. S. (1997). The relationship of the perception of stigma, depression, social support and spirituality to the health status of the individual with HIV/AIDS. Unpublished doctoral dissertation, Florida State University, Tallahassee.

*Braam, A. W., Beekman, A. T. F., Deeg, D. J. H., Smit, J. H., Tilburg, \& W. Van (1997). Religiosity as a protective or prognostic factor of depression in later life: Results from a community survey in the Netherlands. Acta Psychiatrica Scandinavica, 96, 199-205.

*Braam, A. W., Beekman, A. T. F., Tilburg, T. G. van, Deeg, J. H., Tilburg, \& W. Van (1997). Religious involvement and depression in older Dutch citizens. Social Psychiatry Psychiatry Epidemiology, 32, 248-291.

Braam, A. W., van den Eeden, P., Prince, M. J., Beekman, A. T. F., Kivelae, S. L., Lawlor, B. A., Birkhofer, A., Fuhrer, R., Lobo, A., Magnusson, H., Mann, A. H., Meller, I., Roelands, M., Skoog, I., Turrina, C., \& Copeland, J. R. M. (2001). Religion as a crosscultural determinant of depression in elderly Europeans: Results from the EURODEP collaboration. Psychological Medicine, 31, 803-814.

*Brown, D. R., \& Gary, L. E. (1985). Predictors of depressive symptoms among unemployed black adults. Journal of Sociology and Social Welfare, 736-754.

*Brown, D. R., \& Gary, L. E. (1994). Religious involvement and health status among AfricanAmerican males. Journal of the National Medical Association, 86, 825-831.

*Brown, D. R., Gary, L. E., Greene, A. D., \& Milburn, N. G. (1992). Patterns of social affiliation as predictors of depressive symptoms among Blacks. Journal of Health and Social Behavior, 33, 242-253. 
*Brown, D. R., Ndubuisi, S. C., \& Gary, L. E. (1990). Religiosity: A psychological distress among Blacks. Journal of Religion and Health, 29, 55-68.

*Buchanan, D. M. (1993). Meaning in life, depression and suicide in older adults: A comparative survey study. Unpublished doctoral dissertation, Rush University, Chicago, Illinois.

*Burris, C. T. (1994). Curvilinearity and religious types: A second look at intrinsic, extrinsic, and quest relations. The International Journal for the Psychology of Religion, 4, 245-260.

*Carroll, W. C. (1992). Depressed mood in religiously committed persons: A cross-sectional study. Unpublished doctoral dissertation, Loyola College Maryland, Baltimore.

*Chancey, D. (1997). Economic distress and psychological outcomes: Using objective and subjective measures of economic distress and satisfaction moderated by religiosity. Unpublished doctoral dissertation, University of Tennessee, Knoxville.

*Chang, B., Noonan, A. E., \& Tennstedt, S. L. (1998). The role of religion/spirituality in coping with care-giving for disabled elders. The Gerontologist, 38, 463-470.

*Cline, D. J. (1992). The effects of social support on health and religiosity in nursing home elderly. Unpublished doctoral dissertation, Illinois Institute of Technology, Chicago.

*Coates, D. (1996). The correlations of forgiveness of self, forgiveness of others, and hostility, depression, anxiety, self-esteem, life adaptation, and religiosity among female victims of domestic violence. Unpublished doctoral dissertation, California School of Professional Psychology, Fresno.

Cohen, J. (1987). Statistical power analysis for the behavioral sciences. Hillsdale, NJ: Erlbaum. Cohen, S., \& Wills, T. A. (1985). Stress, social support, and the buffering hypothesis. Psychological Bulletin, 98, 310-357. 
*Coleman, C.L. (1996). The effects of religious attributes on psychological well-being and health status in African-Americans living with HIV infection. Unpublished doctoral dissertation, University of California, San Francisco.

*Commerford, M. C. (1996). Relationship of religion and perceived social support to self-esteem and depression in nursing home residents. Unpublished doctoral dissertation, Fordham University, New York, NY.

Cooper, H. (1998). Synthesizing research: A guide for literature reviews (3rd ed.). Thousand Oaks, CA: Sage.

${ }^{*}$ Corzo, D.M. (1981). Perceptions of god, parents, and self as a function of depression and Christian faith. Unpublished doctoral dissertation, Rosemead Graduate School of Professional Psychology, La Mirada, California.

*Crowe, L. T. (1990). Religious value and self-reported depression among college students. Unpublished doctoral dissertation, Indiana University, Bloomington.

Culbertson, F. M. (1997). Depression and gender: An international review. American Psychologist, 52, 25-31.

Donahue, M. J. (1985). Intrinsic and extrinsic religiousness: Review and meta-analysis. Journal of Personality and Social Psychology, 48, 400-419.

D'Onofrio, B. M., Eaves, L. J., Murrelle, L., Maes, H. H., \& Spilka, B. (1999). Understanding biological and social influences on religious affiliation, attitudes, and behaviors: A behavior genetic perspective. Journal of Personality, 67, 953-984.

D’Onofrio, B. M., Murrelle, L., Eaves, L. J., McCullough, M. E., Landis, J. L., \& Maes, H. H. (1999). Adolescent religiousness and its influence on substance use: Preliminary findings from the Mid-Atlantic School Age Twin Study. Twin Research, 2, 156-168. 
*Domanico, R., \& Crawford, I. (2000). Psychological distress among HIV-impacted African American and Latino males. Journal of Prevention and Intervention in the Community,19, 55-78.

*Doxey, C., Jensen, L., \& Jensen, J. (1997). The influence of religion on victims of childhood sexual abuse. International Journal for the Psychology of Religion,7(3), 179-186.

*Ducharme, E. L. (1988). Variations of God concept as a function of depression and incest. Unpublished doctoral dissertation, University of Detroit, Michigan.

Duval, S., \& Tweedie, R. (2000a). A non-parametric “trim and fill” method of accounting for publication bias in meta-analysis. Journal of the American Statistical Association, 95, 8998.

Duval, S., \& Tweedie, R. (2000b). Trim and fill: A simple funnel-plot based method of testing and adjusting for publication bias in meta-analysis. Biometrics, 56, 455-463.

Editorial (1998). Spirit of the age: Malignant sadness is the world's great hidden burden. Economist (December 19), 113-117.

*Ellison, C. G. (1991). Bringing religion back in: The life stress process and the study of depression. Unpublished doctoral dissertation, Duke University, Durham, North Carolina.

Ellison, C. W. (1983). Spiritual well-being: Conceptualization and measurement. Journal of Psychology and Theology, 11, 330-340.

*Faulkner, A.J. (1994). Religious change versus current religiosity: A theoretical explication of the religiosity/well-being association. Unpublished doctoral dissertation, University of Michigan, Ann Arbor. 
*Fehring, R. J., Brennan, P. F., \& Keller, M. L. (1987). Psychological and spiritual well-being in college students. Research in Nursing and Health, 10, 391-398.

*Fehring. R. J., Miller, J. F., \& Shaw, C. (1997). Spiritual well-being, religiosity, hope, depression, and other mood states in elderly people coping with cancer. Oncology Nursing Forum, 24, 663-671.

*Fernando, S. J. M. (1978). Aspects of depression in a Jewish minority group. Psychiatric Clinician, 11, 23-33.

Ferraro, K. F., \& Kelley-Moore, J. A. (2000). Religious consolation among men and women: Do health problems spur seeking? Journal for the Scientific Study of Religion, 39, 220-234.

*Fiori, D. (1991). Impact of identification with God as generative on post menarche adolescent depression. Unpublished doctoral dissertation, Loyola College of Maryland, Baltimore.

*Fitchett, G., Rybarczyk, B. D., DeMarco, G. A., \& Nicholas, J. J. (1999). The role of religion in medical rehabilitation outcomes: A longitudinal study. Rehabilitation Psychology, 44, 333-353.

*Genia, V. \& Shaw, D. G. (1991). Religion, intrinsic-extrinsic orientation, and depression. Review of Religious Research, 32, 274-283.

George, L. K., Larson, D. B., Koenig, H. G., \& McCullough, M. E. (2000). Spirituality and health: What we know, what we need to know. Journal of Social and Clinical Psychology, 19, 102-116.

Granqvist, P. (1998). Religiousness and perceived childhood attachment: On the question of compensation or correspondence. Journal for the Scientific Study of Religion, 37, 350367. 
Grant, B. F. (1995). Comorbidity between DSM-IV drug use disorders and major depression: Results of a national survey of adults. Journal of Substance Abuse, 7, 481-497.

*Gray, R. E. (1987). Adolescent response to death of a parent. Journal of Youth and Adolescence,16, 511-525.

*Griffin, L. A. (1988). Family patterns and parental religiosity in families of depressed and nondepressed adolescents. Unpublished doctoral dissertation, Texas Woman's University, Denton.

*Grosse-Hotforth, M., Pathak, A., Koenig, H. G., Cohen, H. J., Pieper, C. F., \& Vanhook, L. G. (1996). Medical illness, religion, health controls and depression of institutionalized medically ill veterans in long-term care. International Journal of Geriatric Psychiatry, 11, 613-620.

*Gupta, A. (1983). Mental health and religion. Asian Journal of Psychology Education, 11, 8-13.

*Hallstrom, T., \& Persson, G. (1984). The relationship of social setting to major depression. Acta Psychiatrica Scandinavica,70, 327-336.

Hankin, B. L., \& Abramson, L. Y. (2001). Development of gender differences in depression: An elaborated cognitive vulnerability-transactional stress theory. Psychological Bulletin, 127, 773-796.

Hedges, L. V., \& Olkin, I. (1985). Statistical methods for meta-analysis. New York: Academic Press.

Hedges, L. V., \& Vevea, J. L. (1998). Fixed- and random-effects models in meta-analysis. Psychological Methods, 3, 486-504.

*Hertsgaard, D., \& Light, H. (1984). Anxiety, depression, and hostility in rural women. Psychological Reports,55, 673-674. 
*Hettler, T., \& Cohen, L. (1998). Intrinsic religiousness as a stress moderator for adult protestant churchgoers. Journal of Community Psychology, 26, 597-609.

Hill, P. C., \& Hood, R. (1999). Measures of religiosity. Birmingham, AL: Religious Education Press.

Hill, P. C., Pargament, K. I., Hood, R. W., McCullough, M. E., Swyers, J. P., Larson, D. B., \& Zinnbauer, B. J. (2000). Conceptualizing religion and spirituality: Points of commonality, points of departure. Journal for the Theory of Social Behaviour, 30, 51-77.

*Hintikka, J., Viiamaki, H., Koivumaa-Honkanen, H., Tanskanen, A., \& Lehtonen, J. (1998). Associations between religious attendance, social support and depression in psychiatric patients. Journal of Psychology and Theology, 26, 351-357.

Hobson, C. J., Kamen, J., Szostek, J., Nethercut, C. M., Tiedmann, J. W., \& Wojnarowicz, S. (1998). Stressful life events: A revision and update of the Social Readjustment Rating Scale. International Journal of Stress Management, 5, 1-23.

*Hohmann, A. A., Richeport, M., Marriott, B. M., Canino, G. J., Rubio-Stipec, M., \& Bird, H. (1990). Spiritism in Puerto Rico: Results of and island wide community sample. British Journal of Psychiatry, 156, 328-335.

Holmes, T. H., \& Rahe, R. H. (1967). The Social Readjustment Rating Scale. Journal of Psychosomatic Research, 11, 213-218.

*Hong, S., \& Giannakopoulos, E. (1994). The relationship of satisfaction with life to personality characteristics. Journal of Psychology, 128, 547-558.

*Hong, S., \& Mayo, J. (1988). Prediction of depression-proneness. Psychological Reports, 62, 122. 
Hunsberger, B. (1980). A reexamination of the antecedents of apostasy. Review of Religious Research, 21, 158-170.

*Husaini, B., Blasi, A., \& Miller, O. (1999). Does public and private religiosity have a moderating effect on depression? A bi-racial study of elders in the American south. International Journal of Aging and Human Development, 48, 63-72.

*Hyland, K. (1996). The influence of religiosity on an older person's adjustment to the nursing home environment. Unpublished doctoral dissertation, Long Island University, Brookville, New York.

*Idler, E. L. (1987). Religious involvement and the health of the elderly: Some hypotheses and an initial test. Religion and Health, 66, 226-238.

*Idler, E. L., \& Kasl, S. V. (1992). Religion, disability, depression, and the timing of death. American Journal of Sociology, 97, 1052-1079.

Idler, E. L. (1995). Religion, health, and nonphysical senses of self. Social Forces, 74, 683-704.

Ingram, R. E. (1990). Self-focused attention in clinical disorders: A review and conceptual model. Psychological Bulletin, 107, 156-176.

Ingram, R. E., \& Ritter, J. (2000). Vulnerability to depression: Cognitive reactivity and parental bonding in high-risk individuals. Journal of Abnormal Psychology, 109, 588-596.

James, W. (1902). The varieties of religious experience. New York: Longman, Green.

Jennions, M. D., \& Moller, A. P. (2002). Publication bias in ecology and evolution: An empirical assessment using the 'trim and fill’ method. Biological Reviews, 77, 211-222.

*Jensen, L. C., Jensen, J., \& Wiederhold, T. (1993). Religiosity, denomination, and mental health among young men and women. Psychological Reports, 72, 1157-1158. 
Joiner, T., \& Coyne, J. C. (Eds.) (1999). The interactional nature of depression: Advances in interpersonal approaches. Washington, CD: American Psychological Association.

Jorm, A. F., Christensen, H., Henderson, A. S., Jacomb, P. A., Korten, A. E., Rodgers, B. (2000). Predicting anxiety and depression from personality: Is there a synergistic effect of neuroticism and extraversion? Journal of Abnormal Psychology, 109, 145-149.

*Kendler, K. S., Gardner, C. O., \& Prescott, C. A. (1997). Religion, psychopathology, and substance use and abuse: A multi-measure, genetic-epidemiologic study. American Journal of Psychiatry, 154, 322-329.

Kendler, K. S., Gardner, C. O, \& Prescott, C. A. (1999). Clarifying the relationship between religiosity and psychiatric illness: The impact of covariates and the specificity of buffering effects. Twin Research, 2, 137-144.

*Kennedy, G. J., Kelman, H. R., Thomas, C., \& Chen, J. (1996). The relation of religious preference and practice to depressive symptoms among 1,855 older adults. Journal of Gerontology, 51B, 301-308.

Kennedy-Moore, E., \& Watson, J. C. (2001). How and when does emotional expression help? Review of General Psychology, 5, 187-212.

Kirkpatrick, L. A., \& Shaver, P. R. (1990). Attachment theory and religion: Childhood attachments, religious beliefs, and conversion. Journal for the Scientific Study of Religion, 29, 315-334.

*Kivela, S., Kongas-Saviaro, P., Laippala, P., Pahkala, K., \& Kesti, E. (1996). Social and psychosocial factors predicting depression in old age: A longitudinal study. International Psychogeriatrics, 8, 635-644. 
*Klaas, D. (1998). Testing two elements of spirituality in depressed and nondepressed elders. The International Journal of Psychiatric Nursing Research, 4, 452-462.

*Koenig, H. G. (1995). Religion and older men in prison. International Journal of Geriatric Psychiatry, 10, 219-230.

*Koenig, H. G., Cohen, H. J., Blazer, D. G., Pieper, C., Meador, K. G., Shelp, F., Goli, V., \& Dipasquale, B. (1992). Religious coping and depression among elderly, hospitalized medically ill men. America Journal of Psychiatry, 149, 1693-1700.

*Koenig, H. G., George, L. K., Meador, K. G., Blazer, D. G., \& Dyck, P. (1994). Religious affiliation and psychiatric disorder among Protestant baby boomers. Hospital and Community Psychiatry, 45, 586-596.

*Koenig, H. G., George, L. K., \& Peterson, B. L. (1998). Religiosity and remission of depression in medically ill older patients. American Journal of Psychiatry, 155, 536-542.

*Koenig, H. G., Hays, J. C., George, L. K., Blazer, D. G., Larson, D. B., \& Landerman, L. R. (1997). Modeling the cross-sectional relationships between religion, physical health, social support, and depressive symptoms. The American Journal of Geriatric Psychiatry, $5,131-144$.

Koenig, H. G., McCullough, M. E., \& Larson, D. B. (2001). Handbook of religion and health. New York: Oxford Press.

*Koenig, H. G., Moberg, D. O., \& Kvale, J. N. (1988). Religious activities and attitudes of older adults in a geriatric assessment clinic. Journal of American Geriatric Society, 36, 362374. 
*Koenig, H. G., Pargament, K. I., \& Nielsen, J. (1998). Religious coping and health status in medically ill hospitalized older adults. Journal of Nervous and Mental Disease, 186, 513521.

*Kohbod, A. (1996). The interrelationship of acculturation, social support, coping, spiritual well-being, English proficiency, and locus of control to psychological and Iranian depressive symptoms among Iranian immigrants. Unpublished doctoral dissertation, California School of Professional Psychology, Alameda.

*Koteskey, R. L., Little, M. D., \& Matthews, M. V. (1991). Adolescent identity and depression. Journal of Psychology and Christianity,10, 48-53.

Lara, M. E., Leader, J., Klein, D. N. (1997). The association between social support and course of depression: Is it confounded with personality? Journal of Abnormal Psychology,106, 478-482.

Levin, J. S. (2001). God, faith, and health: Exploring the spirituality-healing connection. New York: Wiley.

Levin, J. S., Taylor, R. J., \& Chatters, L. M. (1994). Race and gender differences in religiosity among older adults: Findings from four national surveys. Journals of Gerontology, 49, S137-S145.

*Levin, J. S., Markides, K. S., \& Ray, L. A. (1996). Religious attendance and psychological well-being in Mexican Americans: A panel analysis of three-generations data. The Gerontologist, 36, 454-463.

*Lindgren, K. N., \& Coursey, R. D. (1995). Spirituality and serious mental illness: A two-part study. Psychosocial Rehabilitation Journal, 18, 93-111.

Lipsey, M. W., \& Wilson. D. B. (2001). Practical meta-analysis. Thousand Oaks, CA: Sage. 
*Littrell, J., \& Beck, E. (1999). Perceiving oppression: Relationships with resilience, selfesteem, depressive symptoms, and reliance on God in African-American homeless men. Journal of Sociology and Social Welfare,26, 137-158.

Lyons, L. (1996). The meta-analysis calculator [Computer software]. Manassas, VA: Author.

*Maes, H. H. M., Neale, M. C., Kendler, K. S., Hewitt, J. K., Silberg, J. L., Foley, D. L., Meyer, J. M., Rutter, M., Simonoff, E., Picles, A., \& Eaves, L. J. (1998). Assortive mating for major psychiatric diagnoses in two population-based samples. Psychological Medicine, 28, 1389-1401.

Mahoney, A., Pargament, K. I., \& Tarakeshwar, N. (2001). Religion in the home in the 1980s and 1990s: A meta-analytic review and conceptual analysis of links between religion, marriage, and parenting. Journal of Family Psychology, 15, 559-596.

*Maltby, J., \& Day, L. (2000). Depressive symptoms and religious orientation: Examining the relationship between religiosity and depression within the context of other correlates of depression. Personality and Individual Differences,28, 383-393.

*Maltby, J., Lewis, C. A., \& Day, L. (1999). Religious orientation and psychological well-being: The role of the frequency of personal prayer. British Journal of Health Psychology, 4, 363-378.

*Martin, J. C. (1994). Predictors of functional health in low socioeconomic status, communityliving black older women with osteoarthritis. Unpublished doctoral dissertation, University of Tennessee, Memphis.

*Maton, K. (1989). The stress-buffering role of spiritual support: Cross-sectional and prospective investigations. Journal for the Scientific Study of Religion, 28, 310-323. 
*Mayo, C. C., Puryear, H. B., \& Richek, H. G. (1969). MMPI correlates of religiousness in late adolescent college students. Journal of Nervous and Mental Disease, 149, 381-385.

McCullough, M. E., Hoyt, W.T., Larson, D. B., Koenig, H. G., \& Thoresen, C. E. (2000). Religious involvement and mortality: A meta-analytic review. Health Psychology,19, 211-222.

McCullough, M. E., \& Larson, D. B. (1998). Future directions in research. In H. G. Koenig (Ed.), Handbook of religion and mental health (pp. 95-107). San Diego: Academic Press.

McCullough, M. E., \& Larson, D. B. (1999). Religion and depression: A review of the literature. Twin Research, 2, 126-136.

McCullough, M. E., Worthington, E. L., Jr., Maxey, J., \& Rachal, K. C. (1997). Gender in the context of supportive and challenging religious counseling interventions. Journal of Counseling Psychology, 44, 80-88.

*McDougall, G. J. (1998). Gender differences in coping and control with memory aging. Journal of Women and Aging,10, 21-40.

*McIntosh, B.R., \& Danigelis, N. L. (1995). Race, gender, and the relevance of productive activity for elders' affect. Journal of Gerontology,50B, S229-S239.

Meador, K. G., Koenig, H. G., Hughes, D. C., Blazer, D. G., Turnbull, J., \& George, L. K. (1992). Religious affiliation and major depression. Hospital and Community Psychiatry, 43, 1204-1208.

*Mickley, J.R., Pargament, K. I., Brant, C. R., \& Hipp, K. M. (1998). God and the search for meaning among hospice caregivers. The Hospice Journal,13, 1-17. 
*Miller, L., Warner, V. Wickramaratne, P., \& Weissman, M. (1997). Religiosity and depression: Ten-year follow-up of depressed mothers and offspring. Journal of American Academy of Child and Adolescent Psychiatry,36, 1416-1425.

*Mirola, W. A. (1990). The relationship between religious involvement and depression. Sociology of Religion,60, 419-437.

*Molenkamp, R. J. (1993). An empirical exploration of the existence and relative independence of separate factors for clinical depression and spiritual desolation in a religious population. Unpublished doctoral dissertation, Loyola College Maryland, Baltimore.

Monroe, S. M., \& Simons, A. D. (1991). Diathesis-stress theories in the context of life stress research: Implications for the depressive disorders. Psychological Bulletin, 110, 406-425.

Mor, N., \& Winquist, J. (2002). Self-focused attention and negative affect: A meta-analysis. Psychological Bulletin, 128, 638-662.

*Morse, C. K., \& Wisocki, P. A. (1987). Importance of religiosity to elderly adjustment. Journal of Religion and Aging, 4, 15- 25.

Mosteller, F., \& Colditz, G. A. (1996). Understanding research synthesis (meta-analysis). Annual Review of Public Health, 17, 1-23.

Mullen, B. (1989). Advanced BASIC meta-analysis. Hillside, NJ: Erlbaum.

*Murphy, P. E., Ciarrocchi, J. W., Piedmont, R. L., Cheston, S., Peyrot, M., \& Fitchett, G. (2000). The relation of religious belief and practices, depression, and hopelessness in persons with clinical depression. Journal of Consulting and Clinical Psychology,68, 1102-1106.

*Musick, M. A., Blazer, D. G., \& Hays, J. C. (2000). Religious activity, alcohol use, and depression in a sample of elderly Baptists. Research on Aging, 22, 91-116. 
*Musick, M. A., Koenig, H. G., Hays, J. C., \& Cohen, H. J. (1998). Religious activity and depression among community-dwelling elderly persons with cancer: The moderating effect of race. Journals of Gerontology: Series B: Psychological Sciences and Social Sciences, 53B, S218-S227.

*Musick, M. A., \& Strulowitz, S. (2000). Public religious activity and depressive symptomatology: A comparison of religious groups in the United States. Unpublished manuscript, University of Michigan at Ann Arbor.

*Musick, M. A., Williams, D. R., \& Jackson, J. S. (1998). Race related stress, religion and mental health among African American adults. Unpublished manuscript, University of Michigan at Ann Arbor.

*Neelman, J., \& Lewis, G. (1994). Religious identity and comfort beliefs in three groups of psychiatric patients and a group of medical controls. The International Journal of Social Psychiatry, 40, 124-134.

*Neff, J. A., \& Hoppe, S. K. (1993). Race/ethnicity, acculturation, and psychological distress; fatalism and religiosity as cultural resources. Journal of Community Psychology, 21, 320.

*Nelson, P. B. (1989). Ethnic differences in intrinsic/extrinsic religious orientation and depression in the elderly. Archives of Psychiatric Nursing, 3, 199-204.

*Nelson, P. B. (1989). Social support, self-esteem, and depression in the institutionalized elderly. Issues in Mental Health Nursing, 10, 55-68.

Nezlek, J. B. (2001). Multilevel random coefficient analyses of event- and interval-contingent data in social and personality psychology research. Personality and Social Psychology Bulletin, 27, 771-785. 
NIMH Genetics Workgroup (1998). Genetics and mental disorders. NIH Publication No. 984268. Rockville, MD: National Institute of Mental Health.

Nolen-Hoeksema, S. (1987). Sex differences in unipolar depression: Evidence and theory. Psychological Bulletin, 101, 259-282.

Nolen-Hoeksema, S., Larson, J., \& Grayson, C. (1999). Explaining the gender difference in depressive symptoms. Journal of Personality and Social Psychology, 77, 1061-1072.

Nolen-Hoeksema, S., \& Morrow, J. (1991). A prospective study of depression and posttraumatic stress symptoms after a natural disaster: The 1989 Loma Prieta earthquake. Journal of Personality and Social Psychology, 61, 115-121.

*O'Connor, B. P., \& Vallerand, R. J. (1990). Religious motivation in the elderly: A FrenchCanadian and an extension. Journal of Social Psychology, 3, 38-53.

*O'Laoire, S. (1997). An experimental study of the effects of distant, intercessory prayer on selfesteem, anxiety, and depression. Alternative Therapies, 3(6), 38-53.

*Oler, G. A. (1997). Religious coping and psychological adjustment among African American Christians. Unpublished doctoral dissertation, University of Cincinnati, Ohio.

*Olszewski, M. E. (1994). The effect of religious coping on depression and anxiety in adolescence. Unpublished master’s thesis, Oregon State University, Corvallis.

Owin, R. G. (1994). Evaluating coding decisions. In H. Cooper and L. V. Hedges (Eds.) The handbook of research synthesis (pp. 139-162). New York: Russell Sage Foundation.

*Palinkas, L. A., Wingard, D. L., \& Barret-Connor, E. (1990). The biocultural context of social networks and depression among the elderly. Social Science Medicine, 30, 441-447.

Pargament, K. I. (1997). The psychology of religion and coping. New York: Guilford. 
Pargament, K. I., Ensing, D. S., Falgout, K. Olsen, H., Reilly, B., Van Haitsma, K., \& Warren, R. (1990). God help me: (I): Religious coping efforts as predictors of the outcomes to significant negative life events. American Journal of Community Psychology, 18, 793824.

Pargament, K. I., Koenig, H. G., \& Perez, L. M. (2000). The many methods of religious coping: Development and validation of the RCOPE. Journal of Clinical Psychology, 56, 519-543.

Pargament, K. I., Smith, B. W., Koenig, H. G., \& Perez, L. (1998). Patters of positive and negative religious coping with major life stressors. Journal for the Scientific Study of Religion, 37, 710-724.

Pargament, K. I., Zinnbauer, B., Scott, A., Butter, E., Zerowin, J., \& Stanik, P. (1998). Red flags and religious coping: Identifying some religious warning signs among people in crisis. Journal of Clinical Psychology, 54, 77-89.

*Park, C., Cohen, L. H., \& Herb, L. (1990). Intrinisic religiousness and religious coping as life stress moderators for Catholics versus Protestants. Journal of Personality and Social Psychology, 59, 562-574.

*Park, H. S., Murgatroyd, W. Waynock, D. C., \& Spillet, M. A. (1998). Relationship between intrinisic-extrinsic religious orientation and depressive symptoms in Korean Americans. Counseling Psychology Quarterly, 11, 315-324.

*Patock-Peckham, J. A., Hutchinson, G. T., Cheong, J., \& Nagoshi, C. T. (1998). Effect of religion and religiosity on alcohol use in a college student sample. Drug and Alcohol Dependence, 49, 81-88.

Pincus, H. A., Tanielian, T. L., Marcus, S. C., Olfson, M., Zarin, D. A., Thompson, J., \& Magno Zito, J. (1998). Prescribing trends in psychotropic medications: Primary care, psychiatry, 
and other medical specialties. Journal of the American Medical Association, 279, 256231.

*Plante, T. G., \& Boccaccini, M. T. (1997). The Santa Clara strength of religious faith questionnaire. Pastoral Psychology, 45, 375-387.

Prentice, D. A., \& Miller, D. T. (1992). When small effects are impressive. Psychological Bulletin, 112, 160-164.

*Pressman, P., Lyons, J. S., Larson, D. B., \& Strain, J. J. (1990). Religious belief, depression, and ambulation status in elderly women with broken hips. American Journal of Psychiatry, 147, 758-760.

Putnam, R. D. (2000). Bowling alone. New York: Simon \& Schuster.

*Quinn, W. H., Hazen, P. J., \& Martin, P. (1996). The influence of religiosity, family-of-origin, and self-efficacy on depression in older adults. Journal of Religious Gerontology, 9, 5777.

*Ratanasiripong, P. P. (1996). Effects of culture and religious belief on self-conscious emotions and depression: Acculturation, self-construal, belief in grace, shame, guilt, and depression among Asian American and European American Protestants. Unpublished doctoral dissertation, Wright Institute Graduate School of Psychology, Berkely, CA.

*Renfroe, T. W. (1990). The effect of psychotherapy on spiritual well-being and depression in outpatient adults. Unpublished doctoral dissertation, George Fox College, Newberg, OR.

*Richards, P. S (1991). Religious devoutness in college students: Relations with emotional adjustment and psychological separation from parents. Journal of Counseling Psychology, 38, 189-196. 
Richards, P. S., \& Bergin, A. E. (1997). A spiritual strategy for counseling and psychotherapy. Washington, DC: American Psychological Association.

Richards, P. S., \& Bergin, A. E. (Eds.). (2000). Handbook of psychotherapy and religious diversity. Washington, DC: American Psychological Association.

*Robinson, K. M, \& Kaye, J. (1994). The relationship between spiritual perspective, social support, and depression in caregiving and noncaregiving wives. Scholarly Inquiry for Nursing Practice: An International Journal, 8, 375-389.

*Rosik, C. H. (1989). The impact of religious orientation in conjugal bereavement among older adults. International Journal of Aging and Human Development, 28, 251-260.

Rosenthal, R. (1979). The “file drawer problem” and tolerance for null results. Psychological Bulletin, 86, 638-641.

Rosenthal, R. (1990). How are we doing in soft psychology? American Psychologist, 45, 775777.

*Ross, C. E. (1990). Religion and psychological distress. Journal for the Scientific Study of Religion, 29, 236-245.

*Rowley, L. M. C. (1998). Women in dual-earner marriages. Unpublished doctoral dissertation, Fuller Theological Seminary, Pasadena, CA.

*Ryan, R. M., Rigby, S., \& King, K. (1993). Two types of religious internalization and their relations to religious orientations and mental health. Journal of Personality and Social Psychology, 65, 586-596.

Sacks, H. S., Berrier, J., Reitman, D., Ancova-Berk, V., \& Chalmers, T. C. (1987). Metaanalyses of randomized controlled trials. New England Journal of Medicine, 316, 450455. 
Saz, P., \& Dewey, M. E. (2001). Depression, depressive symptoms and mortality in persons aged 65 and over living in the community: A systematic review of the literature. International Journal of Geriatric Psychiatry, 16, 622-630.

Schnittker, J. (2001). When is faith enough? The effects of religious involvement on depression. Journal for the Scientific Study of Religion, 40, 393-411.

*Schoenbach, V. J., Kaplan, B. H., Grimson, R. C., \& Wagner, E. H. (1982). Use of a symptom scale to study the prevalence of a depressive syndrome in young adolescents. American Journal of Epidemiology, 116, 791-801.

Sethi, S., \& Seligman, M. E. P. (1993). Optimism and fundamentalism. Psychological Science, 4, 256-259.

Shadish, W. R., \& Haddock, C. K. (1994). Combining estimates of effect size. In Cooper, H., \& Hedges, L. V. (Eds.), Handbook of research synthesis (pp. 261-281). New York: Russell Sage.

Schnittker, J. (2001). When is faith enough? The effects of religious involvement on depression. Journal for the Scientific Study of Religion, 40, 393-411.

*Sherkat, D. E., \& Reed, M. D. (1992). The effects of religion and social support on self-esteem and depression among the suddenly bereaved. Social Indicators Research, 26, 259-275.

Shrout, P. E., \& Fleiss, J. L. (1979). Intraclass correlations: Uses in assigning rater reliability. Psychological Bulletin, 86, 420-428.

*Shuler, P. A., Gelberg, L., \& Brown, M. (1994). The effects of spiritual/religious practices on psychological well-being among inner city homeless women. Nurse Practitioner Forum, 5, 106-113. 
*Simon, D. A. (1992). Social support networks and depression in elderly residents of nursing homes. Unpublished doctoral dissertation, Temple University, Philadelphia, PA.

*Snyder, D. L. (1996). The mediating effects of religiosity and irrational beliefs in the differential experiences of guilt and depression in gender-traditional and gendernontraditional men. Unpublished doctoral dissertation, Western Michigan University, Kalamazoo.

*Sorenson, A. M., Grindstaff, C. F., \& Turner, R. J. (1995). Religious involvement among unmarried adolescent mothers: A source of emotional support. Sociology of Religion, 56, 71-81.

*Stavros, G. S. (1998). An empirical study of the impact of contemplative prayer on psychological, relational, and spiritual well-being. Unpublished doctoral dissertation, Boston University, Massachusetts.

*Steer, R. A., \& Schut, J. (1979). Mood components of heroin addicted men: Psychosocial correlates. The International Journal of the Addictions, 14, 1171-1176.

Steinfeld, G. (1999). Brief therapy with a postpartum depressive: Integrating cognitive-behavior and thought field therapies within a spiritual framework. Journal of Psychotherapy Integration, 9, 337-363.

*Strawbridge, W. J., Shema, S. J., Cohen, R. D., Roberts, R. E., \& Kaplan, G. A. (1998). Religiosity buffers effects of some stressors on depression but exacerbates others. Journal of Gerontology, 53B, S118-S126.

*Strayhorn, J. M., Weidman, C. S., \& Larson, D. (1990). A measure of religiousness, and its relation to parent and child mental health variables. Journal of Community Psychology, 18, 34-43. 
Sutton, A. J., Song, F., Gilbody, S. M., \& Abrams, K. R. (2000). Modelling publication bias in meta-analysis: A review. Statistical Methods in Medical Research, 9, 421-445.

Taylor, R. J., Chatters, L. M., Jayakody, \& Levin, J. S. (1996). Black and white differences in religious participation: A multisample comparison. Journal for the Scientific Study of Religion, 35, 403-410.

*Teel, C. S. H. (1993). Grief, recurrent sorrow, and depression among caregivers and bereaved. Unpublished doctoral dissertation, University of Arizona, Tucson.

*Thearle, M. J., Vance, J. C., Najman, J. M., Embelton, G., \& Foster, W. J. (1995). Church attendance, religious affiliation and parental responses to sudden infant death, neonatal death and stillbirth. OMEGA, 31, 51-58.

*Trent, J. R., Keller, J. W., \& Piotrowski, C. (1983). Religious orientation and mental health measured by the Minnesota Multiphasic Personality Inventory. Unpublished doctoral dissertation, University of West Florida, Pensacola.

Trimble, D. E. (1997). Religious Orientation Scale: Review and meta-analysis of social desirability effects. Educational and Psychological Measurement, 57, 970-986.

Tsang, J., \& McCullough, M. E. (in press). Measuring religious constructs: A hierarchical approach to construct organization and scale selection. In S. J. Lopez and C. R. Snyder (Eds.), Handbook of positive psychological assessment. Washington, D.C.: American Psychological Association.

Twenge, J., \& Nolen-Hoeksema, S. (2001). Age, gender, race, SES, and birth cohort differences on the Children's Depression Inventory: A meta-analysis. Manuscript submitted for publication. 
*Vaillant, G. E., Meyer, S. E., Mukamal, K., \& Soldz, S. (1998). Are social supports in late midlife a cause or a result of successful physical aging? Psychological Medicine, 28, 1159-1168.

*VandeCreek, L., Pargament, K., Belavich, T., Cowell, B., \& Friedel, L. (1995, August). The role of religious support when coping with surgical anxieties. Paper presented at the $103^{\text {rd }}$ Convention of the American Psychological Association, New York, NY.

*Virginia, S. G. (1998). Burnout and depression among Roman Catholic secular, religious, and monastic clergy. Pastoral Psychology, 47, 49-67.

Waller, N., Kojetin, B., Bouchard, T., Jr., Lykken, D., \& Tellegen, A. (1990). Genetic and environmental influences on religious interests, attitudes, and values: A study of twins reared apart and together. Psychological Science, 1, 138-142.

*Watson, P. J., Morris, R. J., \& Hood, R. W. (1989). Intrinsicness, religious self-love, and narcissism. Journal of Psychology and Christianity, 8, 31-37.

*Watson, P. J., Morris, R. J., \& Hood, R. W. (1989). Sin and self-functioning, Part 4: Depression, assertiveness, and religious commitments. Journal of Psychology and Theology, 17, 44-58.

*Watson, P. J., Morris, R. J., \& Hood, R. W. (1992). Quest and identity within a religious ideological surround. Journal of Psychology and Theology, 20, 376-388.

*Watson, P. J., Morris, R. J., \& Hood, R. W. (1993). Mental health, religion and the ideology of irrationality. Research in the Social Scientific Study of Religion, 5, 53-88.

*Watson, P. J., Morris, R. J., \& Hood, R. W. (1994). Religion and rationality: Rational-Emotive and religious understandings of perfectionism and other irrationalities. Journal of Psychology and Christianity, 13, 356-372. 
*Watson, P. J., Morris, R. J., Hood, R. W., \& Folbrecht, J. (1990). Dependency, "irrationality," and community. Journal of Psychology and Theology, 18, 334-347.

*Wilson, H. P. (1994). Forgiveness and survivors of sexual abuse: Relationships among forgiveness of the perpetrator, spiritual well-being, depression and anxiety. Unpublished doctoral dissertation, Boston University, Massachusetts.

Wilson, J., \& Sherkat, D. E. (1994). Returning to the fold. Journal for the Scientific Study of Religion, 33, 148-161.

*Woods, T. E., Antoni, M. H., Ironson, G. H., \& Kling, D. W. (1999). Religiosity is associated with affective and immune status in HIV-infected gay men. Journal of Psychosomatic Research, 46, 165-176.

*Wright, L. S., Frost, C. J., \& Wisecarver, S. J. (1993). Church attendance, meaningfulness of religion, and depressive symptomology among adolescents. Journal of Youth and Adolescence, 22, 559-568.

Wulsin, L. R., Vaillant, G. E., \& Wells, V. E. (1999). A systematic review of the mortality of depression. Psychosomatic Medicine, 61, 6-17.

*Wyatt, G. K., Friedman, L. L., Given, C. W., Given, B. A., \& Beckrow, K. C. (1999). Complementary therapy use among older cancer patients. Cancer Practice, 7, 136-144.

*Zhang, J., \& Jin, S. (1996). Determinants of suicidal ideation: A comparison of Chinese and American college students. Adolescence, 31, 451-467.

Zorilla, E., Luborsky, L., McKay, J., Rosenthal, R., Houldin, A., Tax, A., McCorkle, R>, Seligman, D., \& Schmidt, K. (2001). The relationship of depression and stressors to immunological assays: A meta-analytic review. Brain, Behavior, and Immunity, 15, 199226. 
*Zunzunegui, M. V., Beland, F., Llacer, A., \& Keller, I. (1999). Family, religion, and depressive symptoms in caregivers of disabled elderly. Journal of Epidemiology and Community Health, 53, 364-369. 


\begin{abstract}
Author Notes
Timothy B. Smith, Department of Counseling Psychology, Brigham Young University, Provo, UT. Michael E. McCullough, Department of Psychology, University of Miami, FL. Justin Poll, Department of Counseling Psychology, Brigham Young University, Provo, UT. Work on this article was supported by grants from the John Templeton Foundation, the Campaign for Forgiveness Research, TP Industrials Inc., and the Religious Research Association. Correspondence regarding this article may be sent either to Timothy B. Smith, 340 MCKB, Provo, UT 84602-5093, e-mail: timsmith@byu.edu or Michael E. McCullough, Department of Psychology, University of Miami, P.O. Box 248185, Coral Gables, FL 33124-2070, e-mail: mmccullough@umiami.ir.miami.edu. We thank Sharon Black, Rick Ingram, and Michael Lambert for their helpful comments on previous drafts on this article and Brandon Dickson, Tiffany Martin, and Jim Scriber for their work as coders.
\end{abstract}


Table 1

Characteristics of Studies Included in Meta-Analysis

\begin{tabular}{|c|c|}
\hline Characteristic & $\begin{array}{l}\text { Number of } \\
\text { studies (k) }\end{array}$ \\
\hline \multicolumn{2}{|l|}{ Year of report } \\
\hline Before 1990 & 27 \\
\hline $1990-1994$ & 54 \\
\hline $1995-2000$ & 66 \\
\hline \multicolumn{2}{|l|}{ Field of Inquiry } \\
\hline Psychology & 56 \\
\hline Medicine & 42 \\
\hline Nursing & 15 \\
\hline Sociology & 15 \\
\hline Religious Studies & 13 \\
\hline Other (e.g., Education) & 6 \\
\hline \multicolumn{2}{|l|}{ Population sampled } \\
\hline Adults from the general population & 44 \\
\hline College students & 30 \\
\hline Adults receiving medical care & 23 \\
\hline Adults with psychological concerns (e.g., outpatients, bereaved) & 19 \\
\hline Adults from religious settings & 15 \\
\hline Other (e.g., caregivers, adolescents) & 16 \\
\hline \multicolumn{2}{|l|}{ Sampling procedure used } \\
\hline Convenience & 88 \\
\hline Representative & 34 \\
\hline Unable to determine from report & 27 \\
\hline \multicolumn{2}{|l|}{ Sample size } \\
\hline$<50$ & 14 \\
\hline $50-100$ & 32 \\
\hline $100-250$ & 41 \\
\hline $251-1000$ & 37 \\
\hline$>1001$ & 23 \\
\hline \multicolumn{2}{|l|}{ Design } \\
\hline Cross-sectional & 125 \\
\hline Longitudinal & 15 \\
\hline Other (e.g., archival, experimental) & 7 \\
\hline
\end{tabular}


Table 2

Descriptions of the 147 Individual Studies Included in the Meta-Analysis.

\begin{tabular}{|c|c|c|c|c|c|c|c|c|c|}
\hline Study & $\underline{N}$ & $\begin{array}{l}\text { Mean } \\
\text { Age }\end{array}$ & $\begin{array}{l}\text { Sample } \\
\text { Type }\end{array}$ & $\begin{array}{l}\text { Stressful } \\
\text { Life } \\
\text { Events }\end{array}$ & $\begin{array}{l}\text { Level of } \\
\text { Depression }\end{array}$ & $\begin{array}{c}\text { Type of Religious } \\
\text { Measure }\end{array}$ & $\begin{array}{l}\text { Effect } \\
\text { Size } \\
\text { (r) }\end{array}$ & $\begin{array}{l}\quad 95 \% \\
\text { Lower } \\
\text { Limit }\end{array}$ & $\begin{array}{l}\text { CI } \\
\text { Upper } \\
\text { Limit }\end{array}$ \\
\hline Austin \& Lennings (1993) & 57 & 33 & Grieving/ bereaved adults & Moderate & Moderate & Multidimensional & -0.03 & -0.29 & 0.24 \\
\hline Baird (1990) & 164 & 16 & High school students & Minimal & Mild & Multidimensional & -0.17 & -0.32 & -0.02 \\
\hline Bekaroglu, Uluutku, Tariover, \& & & & Nursing home residents \& & & & & & & \\
\hline Kirpinar (1991) & 292 & 72 & normal elderly adults & Mild & Mild & Religious behaviors & -0.31 & -0.41 & -0.21 \\
\hline Belavich (1995) & 222 & 19 & University students & Minimal & Minimal & Religious coping & -0.09 & -0.22 & 0.04 \\
\hline Bergin, Masters, \& Richards & & (Young & & & & & & & \\
\hline (1987) & 32 & adults) & Religious university students & Minimal & Minimal & Religious orientation & 0.02 & -0.34 & 0.36 \\
\hline \multicolumn{10}{|l|}{ Bickel, Ciarrocchi, Sheers, } \\
\hline \multicolumn{10}{|l|}{ Estadt, Powell, \& Pargament } \\
\hline (1998) & 245 & 53 & Church members & Minimal & Minimal & Religious coping & 0.00 & -0.13 & -0.13 \\
\hline Bienenfeld, Koenig, Larson, \& & & (Senior & & & & & & & \\
\hline Sherrill (1997) & 89 & adults) & Religious nursing home residents & Mild & Minimal & Religious orientation & -0.40 & -0.58 & -0.22 \\
\hline
\end{tabular}


Table 2 (continued). Descriptions of the 147 Individual Studies Included in the Meta-Analysis.

\begin{tabular}{|c|c|c|c|c|c|c|c|c|}
\hline Study & $\underline{N}$ & Mean & Sample & Stressful & Level of & Type of Religious & Effect & $95 \% \mathrm{CI}$ \\
\hline & & Age & Type & $\begin{array}{l}\text { Life } \\
\text { Events }\end{array}$ & Depression & Measure & $\begin{array}{l}\text { Size } \\
(\mathrm{r})\end{array}$ & $\begin{array}{ll}\text { Lower } & \text { Upper } \\
\text { Limit } & \text { Limit }\end{array}$ \\
\hline
\end{tabular}

Biggar, Forehand, Devine,

Brody, Armistead, Morse, \&

Simon (1999)

Bishop, Larson, \& Wilson

(1987)

Blaine \& Crocker (1995)

Blumel (1993)

Bohrnstedt, Borgatta, \& Evans

(1968)

Bozarth (1997)

Braam, Beekman, Deeg, Smit, \&

Tilburg (1997)

Braam, Beekman, Tilburg, Deeg,

\& Tilburg (1997)

HIV positive adults \& normal

Psychiatric inpatients \& normal

173 (Adults) adults

$146 \quad 20 \quad$ University students

12007 (Adults) Normal adults

(Young

3666 adults) University students

43 (Adults) HIV positive adults

(Senior

177 adults) Normal senior adults

2817

$70 \quad$ Normal adults
Moderate Minimal Multidimensional

$0.00 \quad-0.14$

$\begin{array}{lccccc}\text { Severe } & \text { Moderate } & \text { Religious attitudes } & -0.16 & -0.31 & -0.02 \\ \text { Minimal } & \text { Minimal } & \text { Multidimensional } & -0.06 & -0.22 & 0.11 \\ & & & & & \\ \text { Minimal } & \text { Minimal } & \text { Religious behaviors } & -0.06 & -0.08 & -0.04\end{array}$

$\begin{array}{llllll}\text { Minimal } & \text { Minimal } & \text { Religious attitudes } & -0.18 & -0.22 & -0.15 \\ \text { Severe } & \text { Moderate } & \text { Religious well-being } & -0.10 & -0.40 & 0.20\end{array}$

Mild $\quad$ Mild $\quad$ Religious attitudes $\quad-0.30 \quad-0.43 \quad-0.16$

Minimal Minimal Multidimensional $\quad-0.09 \quad-0.13 \quad-0.05$ 
Table 2 (continued). $\quad$ Descriptions of the 147 Individual Studies Included in the Meta-Analysis.

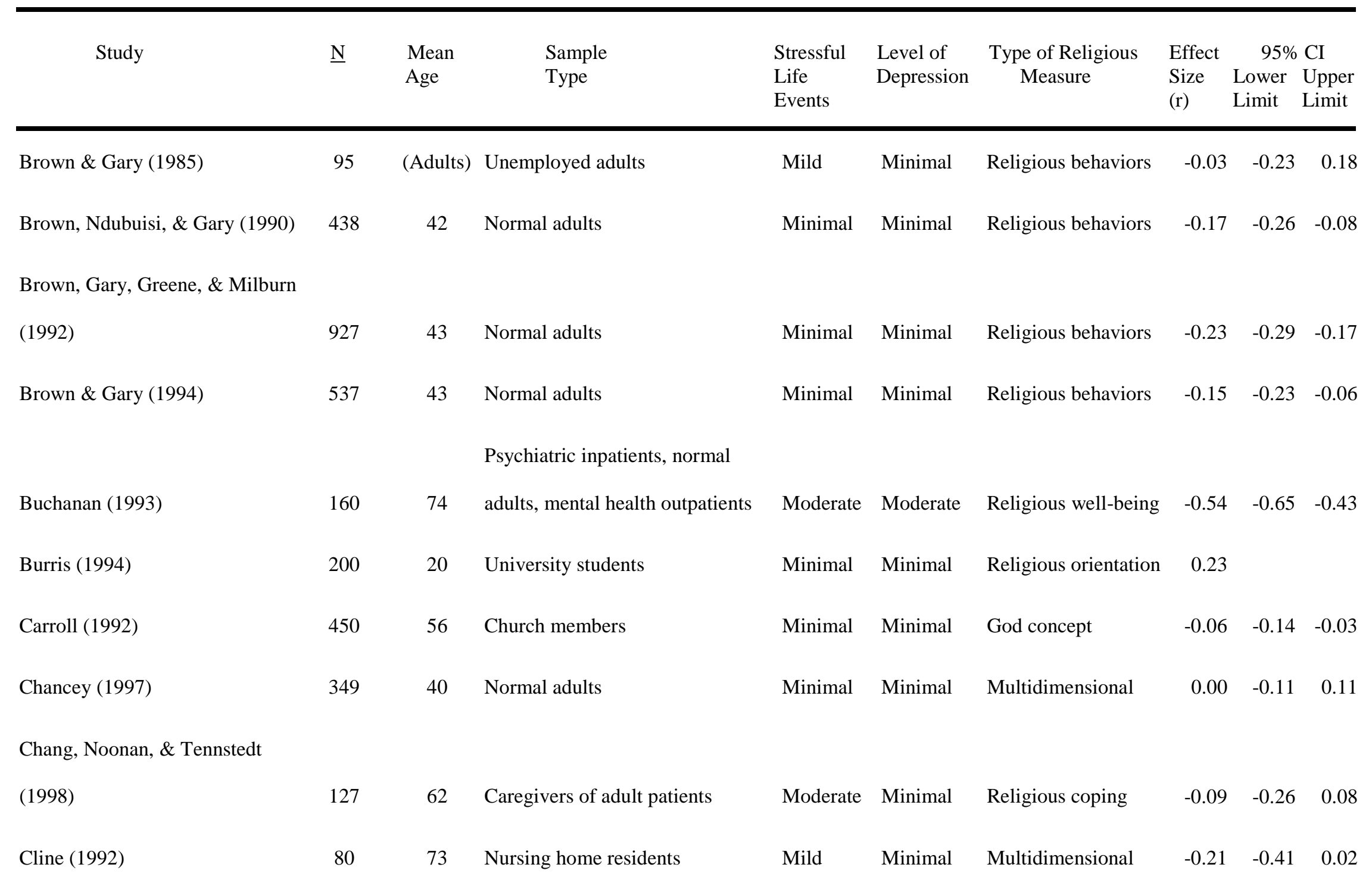


Table 2 (continued). $\quad$ Descriptions of the 147 Individual Studies Included in the Meta-Analysis.

\begin{tabular}{|c|c|c|c|c|c|c|c|c|c|}
\hline Study & $\underline{\mathrm{N}}$ & $\begin{array}{l}\text { Mean } \\
\text { Age }\end{array}$ & $\begin{array}{l}\text { Sample } \\
\text { Type }\end{array}$ & $\begin{array}{l}\text { Stressful } \\
\text { Life } \\
\text { Events }\end{array}$ & $\begin{array}{l}\text { Level of } \\
\text { Depression }\end{array}$ & $\begin{array}{l}\text { Type of Religious } \\
\text { Measure }\end{array}$ & $\begin{array}{l}\text { Effect } \\
\text { Size } \\
(r)\end{array}$ & $\begin{array}{l}\quad 95 \% \\
\text { Lower } \\
\text { Limit }\end{array}$ & $\begin{array}{l}6 \text { CI } \\
\text { Upper } \\
\text { Limit }\end{array}$ \\
\hline Coates (1996) & 100 & 38 & Abuse victims & Moderate & Minimal & Religious orientation & -0.02 & $2-0.22$ & 0.18 \\
\hline Coleman (1996) & 116 & 38 & HIV positive adults & Severe & Moderate & Religious well-being & -0.21 & $1 \quad-0.38$ & -0.03 \\
\hline \multirow[t]{2}{*}{ Commerford (1996) } & 81 & 81 & Nursing home residents & Mild & Mild & Religious orientation & -0.05 & -0.27 & 0.17 \\
\hline & & & Psychiatric inpatients \& normal & & & & & & \\
\hline Corzo (1981) & 123 & 36 & adults & Mild & Moderate & God concept & 0.00 & -0.18 & 0.18 \\
\hline Crowe (1990) & 389 & 20 & University students & Minimal & Minimal & Religious orientation & 0.07 & $7 \quad-0.03$ & 0.17 \\
\hline Domanico \& Crawford (2000) & 96 & 37 & HIV positive adults & Severe & Minimal & Religious well-being & -0.45 & -0.61 & -0.29 \\
\hline \multirow[t]{2}{*}{ Doxey, Jensen, \& Jensen (1997) } & 4920 & 20 & University students & Minimal & Minimal & Religious attitudes & -0.10 & -0.13 & -0.07 \\
\hline & & & Psychiatric inpatients \& normal & & & & & & \\
\hline Ducharme (1988) & 57 & 39 & adults & Severe & Moderate & God concept & -0.29 & -0.53 & -0.05 \\
\hline Ellison (1991) & 2956 & 43 & Normal adults & Minimal & Minimal & Multidimensional & 0.02 & -0.02 & 0.05 \\
\hline Faulkner (1994) & 2834 & 59 & Normal adults & Minimal & Minimal & Multidimensional & 0.02 & -0.01 & 0.06 \\
\hline
\end{tabular}


Table 2 (continued). $\quad$ Descriptions of the 147 Individual Studies Included in the Meta-Analysis.

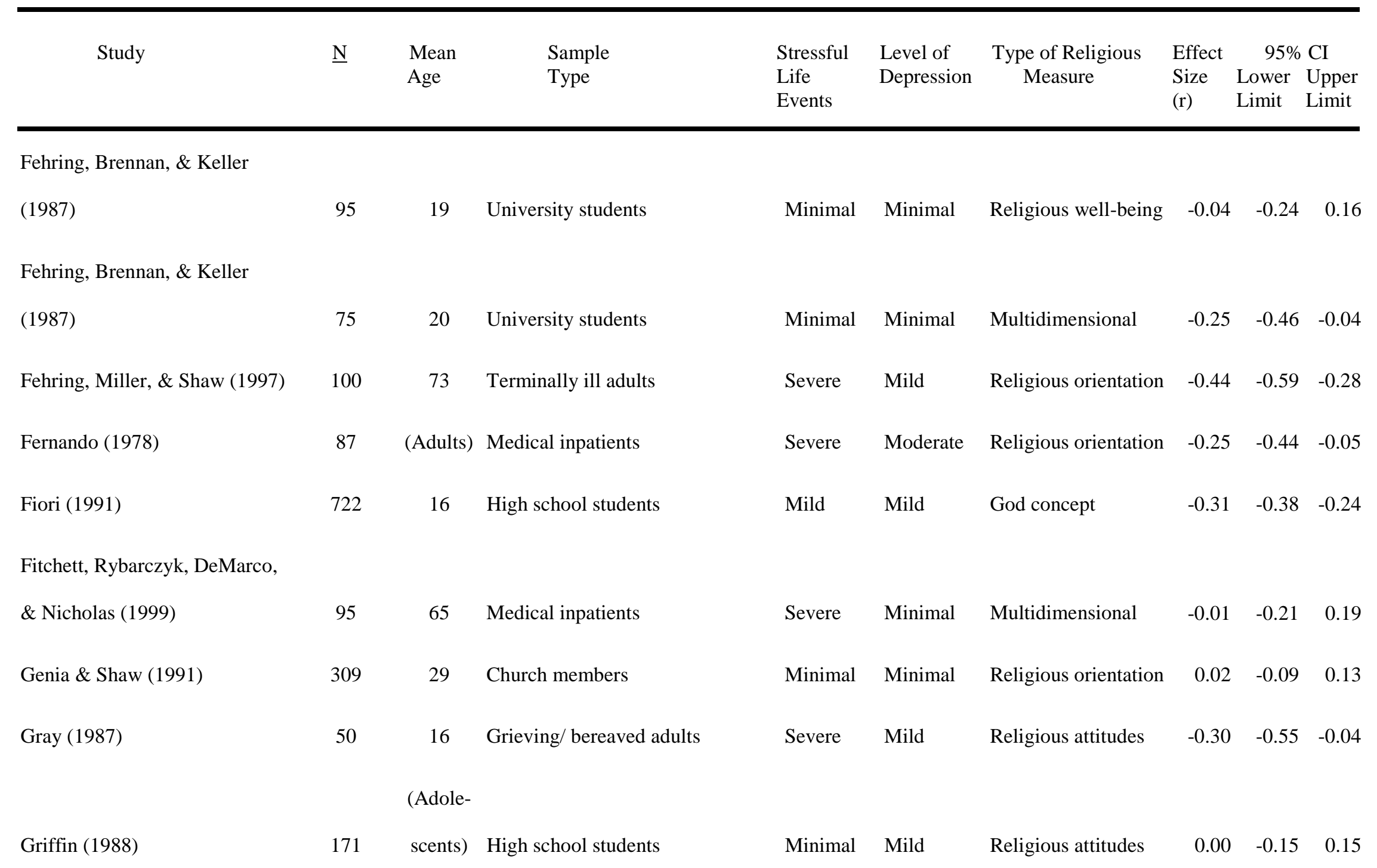


Table 2 (continued). Descriptions of the 147 Individual Studies Included in the Meta-Analysis.

\begin{tabular}{|c|c|c|c|c|c|c|c|c|}
\hline Study & $\underline{\mathrm{N}}$ & Mean & Sample & Stressful & Level of & Type of Religious & Effect & $95 \%$ CI \\
\hline & & Age & Type & $\begin{array}{l}\text { Life } \\
\text { Events }\end{array}$ & Depression & Measure & $\begin{array}{l}\text { Size } \\
(r)\end{array}$ & $\begin{array}{ll}\text { Lower } & \text { Upper } \\
\text { Limit } & \text { Limit }\end{array}$ \\
\hline
\end{tabular}

Grosse-Hotforth, Pathak,

Koenig, Cohen, Pieper, \&

Vanhook (1996)

Gupta (1983)

allstrom \& Persson (1984)

Hertsgaard \& Light (1984)

Hettler \& Cohen (1998)

Hintikka, Viiamaki, Koivumaa-

Honkanen, Tanskanen, \&

Lehtonen (1998)
Mental health outpatients \&

$\begin{array}{lll}453 & 47 & \text { normal adults } \\ 760 & 44 & \text { Normal adults } \\ 124 & 48 & \text { Church members }\end{array}$

$124 \quad 48 \quad$ Church members
41 Mental health outpatients

$\begin{array}{llllll}\text { Moderate } & \text { Mild } & \text { Multidimensional } & -0.25 & -0.43 & -0.06 \\ \text { Minimal } & \text { Minimal } & \text { Religious attitudes } & 0.24 & 0.13 & 0.34 \\ & & & & & \\ & & & & & \\ \text { Severe } & \text { Moderate } & \text { Multidimensional } & -0.07 & -0.16 & 0.02 \\ \text { Minimal } & \text { Minimal } & \text { Religious behaviors } & -0.13 & -0.20 & -0.06 \\ & & & & & \\ \text { Minimal } & \text { Minimal } & \text { Multidimensional } & -0.01 & -0.18 & 0.17\end{array}$

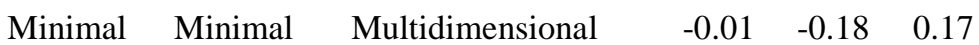


Hohmann, Richeport, Marriott,

Canino, Rubio-Stipec, \& Bird

(1990)

653 (Adults) Normal adults

Minimal Minimal Religious well-being

$0.11 \quad 0.03$

0.19

Table 2 (continued). $\quad$ Descriptions of the 147 Individual Studies Included in the Meta-Analysis.

\begin{tabular}{|c|c|c|c|c|c|c|c|c|c|}
\hline Study & $\underline{\mathrm{N}}$ & $\begin{array}{l}\text { Mean } \\
\text { Age }\end{array}$ & $\begin{array}{l}\text { Sample } \\
\text { Type }\end{array}$ & $\begin{array}{l}\text { Stressful } \\
\text { Life } \\
\text { Events }\end{array}$ & $\begin{array}{l}\text { Level of } \\
\text { Depression }\end{array}$ & $\begin{array}{l}\text { Type of Religious } \\
\text { Measure }\end{array}$ & $\begin{array}{l}\text { Effect } \\
\text { Size } \\
(\mathrm{r})\end{array}$ & $\begin{array}{l}\quad 95 \% \\
\text { Lower } \\
\text { Limit }\end{array}$ & $\begin{array}{l}\text { o CI } \\
\text { Upper } \\
\text { Limit }\end{array}$ \\
\hline & & (Young & & & & & & & \\
\hline Hong \& Mayo (1988) & 208 & adults) & University students & Minimal & Minimal & Religious attitudes & 0.04 & -0.09 & 0.18 \\
\hline Hong \& Giannakopoulos (1994) & 1722 & 25 & Normal adults & Minimal & Minimal & Religious attitudes & -0.06 & -0.10 & -0.01 \\
\hline Husaini, Blasi, \& Miller (1999) & 995 & 72 & Normal adults & Minimal & Minimal & Religious behaviors & -0.15 & -0.21 & -0.08 \\
\hline Hyland (1996) & 60 & 81 & Nursing home residents & Mild & Minimal & Multidimensional & -0.19 & -0.42 & 0.07 \\
\hline Idler (1987) & 2756 & 74 & Normal elderly adults & Minimal & Moderate & Multidimensional & -0.13 & -0.17 & -0.09 \\
\hline Idler \& Kasl (1992) & 1447 & (Elderly) & Normal elderly adults & Minimal & Minimal & Multidimensional & -0.04 & -0.09 & 0.01 \\
\hline Jensen, Jensen, \& Wiederhold & & & & & & & & & \\
\hline (1993) & 3835 & 21 & University students & Minimal & Minimal & Religious attitudes & -0.06 & -0.09 & -0.03 \\
\hline
\end{tabular}


Kendler, Gardner, \& Prescott

Kennedy, Kelman, Thomas, \&

Chen (1996)

Table 2 (continued). Descriptions of the 147 Individual Studies Included in the Meta-Analysis.

\begin{tabular}{|c|c|c|c|c|c|c|c|c|}
\hline Study & $\underline{N}$ & Mean & Sample & Stressful & Level of & Type of Religious & Effect & $95 \% \mathrm{CI}$ \\
\hline & & Age & Type & $\begin{array}{l}\text { Life } \\
\text { Events }\end{array}$ & Depression & Measure & $\begin{array}{l}\text { Size } \\
(\mathrm{r})\end{array}$ & $\begin{array}{ll}\text { Lower } & \text { Upper } \\
\text { Limit } & \text { Limit }\end{array}$ \\
\hline
\end{tabular}

Kivela, Kongas-Saviaro,

Laippala, Pahkala, \& Kesti

(1996)

Klaas (1998)

Koenig, Moberg, \& Kvale

Koenig, Cohen, Blazer, Pieper,

Meador, Shelp, Goli, \&

Dipasquale (1992)

$\begin{array}{llllll}\text { Minimal } & \text { Minimal } & \text { Religious behaviors } & -0.35 & -0.42 & -0.29 \\ \text { Minimal } & \text { Minimal } & \text { Religious attitudes } & -0.11 & -0.33 & 0.11\end{array}$

Minimal Mild Multidimensional

$\begin{array}{lll}-0.20 & -0.40 & -0.01\end{array}$ 
Koenig, Cohen, Blazer, Pieper,

Meador, Shelp, Goli, \&

Dipasquale (1992)

Koenig (1995)
(Senior

202 adults) Medical inpatients

$96 \quad 57 \quad$ Prisoners

$\begin{array}{llllll}\text { Severe } & \text { Mild } & \text { Religious coping } & -0.24 & -0.37 & -0.11 \\ \text { Severe } & \text { Minimal } & \text { Multidimensional } & -0.17 & -0.37 & 0.02\end{array}$

Table 2 (continued). Descriptions of the 147 Individual Studies Included in the Meta-Analysis.

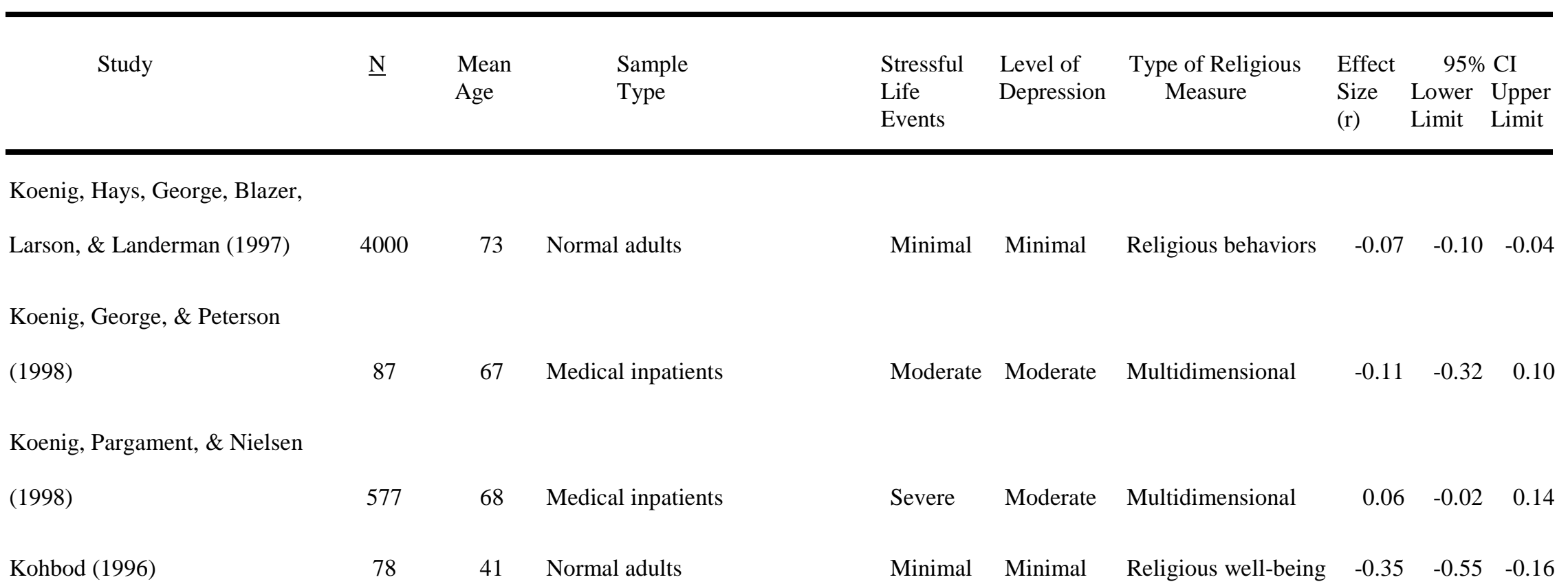


Religiousness and Depressive Symptoms 80

Koteskey, Little, \& Matthews

$\begin{array}{lcclllllllll}\text { (1991) } & 109 & 19 & \text { University students } & \text { Minimal } & \text { Minimal } & \text { Religious orientation } & -0.29 & -0.46 & -0.12 \\ \text { Levin, Markides, \& Ray (1996) } & 617 & 55 & \text { Normal adults } & \text { Minimal } & \text { Minimal } & \text { Religious behaviors } & -0.02 & -0.10 & 0.05 \\ \text { Lindgren \& Coursey (1995) } & 30 & 41 & \text { Mental health outpatients } & \text { Severe } & \text { Mild } & \text { Religious behaviors } & -0.42 & -0.72 & -0.12 \\ \text { Littrell \& Beck (1999) } & 91 & 38 & \text { Homeless adults } & \text { Severe } & \text { Minimal } & \text { Religious coping } & 0.00 & -0.21 & 0.21\end{array}$

Table 2 (continued). Descriptions of the 147 Individual Studies Included in the Meta-Analysis.

\begin{tabular}{|c|c|c|c|c|c|c|c|c|}
\hline Study & $\underline{\mathrm{N}}$ & Mean & Sample & Stressful & Level of & Type of Religious & Effect & 95\% CI \\
\hline & & Age & Type & $\begin{array}{l}\text { Life } \\
\text { Events }\end{array}$ & Depression & Measure & $\begin{array}{l}\text { Size } \\
(r)\end{array}$ & $\begin{array}{ll}\text { Lower Upper } \\
\text { Limit } & \text { Limit }\end{array}$ \\
\hline
\end{tabular}

Maes, Neale, Kendler, Hewitt,

Silberg, Foley, Meyer, Rutter,

Simonoff, Picles, \& Eaves

$\begin{array}{lcclllllllll}\text { (1998) } & 2844 & 48 & \text { Normal adults } & \text { Minimal } & \text { Minimal } & \text { Religious behaviors } & -0.06 & -0.10 & -0.02 \\ \text { Maltby \& Day (2000) } & 360 & 20 & \text { University students } & \text { Minimal } & \text { Minimal } & \text { Multidimensional } & 0.11 & 0.01 & 0.21 \\ \text { Maltby, Lewis, \& Day (1999) } & 474 & 20 & \text { University students } & \text { Minimal } & \text { Minimal } & \text { Multidimensional } & 0.00 & -0.09 & 0.09 \\ \text { Martin (1994) } & 100 & 76 & \text { Medical outpatients } & \text { Moderate } & \text { Minimal } & \text { Multidimensional } & -0.14 & -0.33 & 0.05\end{array}$


Religiousness and Depressive Symptoms 81

\begin{tabular}{|c|c|c|c|c|c|c|c|c|c|}
\hline Maton (1989) & 81 & 46 & Grieving/ bereaved adults & Moderate & Minimal & Religious coping & -0.23 & -0.44 & -0.02 \\
\hline & & (Young & & & & & & & \\
\hline Mayo, Puryear, \& Richek (1969) & 165 & adults) & University students & Minimal & Minimal & Religious attitudes & -0.19 & -0.33 & -0.04 \\
\hline McDougall (1998) & 169 & 68 & Normal adults & Minimal & Minimal & Religious coping & -0.08 & -0.23 & 0.07 \\
\hline & & (Senior & & & & & & & \\
\hline McIntosh \& Danigelis (1995) & 1644 & adults) & Normal adults & Minimal & Minimal & Religious behaviors & -0.30 & -0.34 & -0.26 \\
\hline
\end{tabular}

Table 2 (continued). $\quad$ Descriptions of the 147 Individual Studies Included in the Meta-Analysis.

\begin{tabular}{|c|c|c|c|c|c|c|c|c|c|}
\hline Study & $\underline{\mathrm{N}}$ & $\begin{array}{l}\text { Mean } \\
\text { Age }\end{array}$ & $\begin{array}{l}\text { Sample } \\
\text { Type }\end{array}$ & $\begin{array}{l}\text { Stressful } \\
\text { Life } \\
\text { Events }\end{array}$ & $\begin{array}{l}\text { Level of } \\
\text { Depression }\end{array}$ & $\begin{array}{l}\text { Type of Religious } \\
\text { Measure }\end{array}$ & $\begin{array}{l}\text { Effect } \\
\text { Size } \\
(\mathrm{r})\end{array}$ & $\begin{array}{l}\quad 95 \% \\
\text { Lower } \\
\text { Limit }\end{array}$ & $\begin{array}{l}\text { CI } \\
\text { Upper } \\
\text { Limit }\end{array}$ \\
\hline Mickley, Pargament, & & & & & & & & & \\
\hline Hipp (1998) & 92 & 57 & Caregivers of adult patients & Moderate & Minimal & Multidimensional & -0.16 & -0.35 & 0.05 \\
\hline Miller, Warner, Wicl & & & & & & & & & \\
\hline \& Weissman (1997) & 60 & 55 & Normal adults & Minimal & Moderate & Multidimensional & -0.33 & -0.56 & -0.11 \\
\hline Mirola (1990) & 700 & (Adults) & Normal adults & Minimal & Minimal & Multidimensional & -0.13 & -0.20 & -0.06 \\
\hline Molenkamp (1993) & 394 & 45 & Church members & Minimal & Minimal & Multidimensional & -0.12 & -0.22 & -0.02 \\
\hline
\end{tabular}


Religiousness and Depressive Symptoms 82

Morse \& Wisocki (1987)

Murphy, Ciarrocchi, Piedmont,

Cheston, Peyrot, \& Fitchett

Musick, Blazer, \& Hays (2000)

Psychiatric inpatients \& mental

1897

\section{1 (Adults) health outpatients}

73 Church members
Severe Moderate Religious well-being

Minimal Minimal Religious behaviors
$-0.32 \quad-0.42 \quad-0.21$

$\begin{array}{lll}0.01 & -0.04 & 0.05\end{array}$

Musick, Koenig, Hays, \& Cohen

(1998)

$235 \quad 73 \quad$ Normal adults

Minimal Minimal

Religious behaviors

$-0.03$

Table 2 (continued). Descriptions of the 147 Individual Studies Included in the Meta-Analysis.

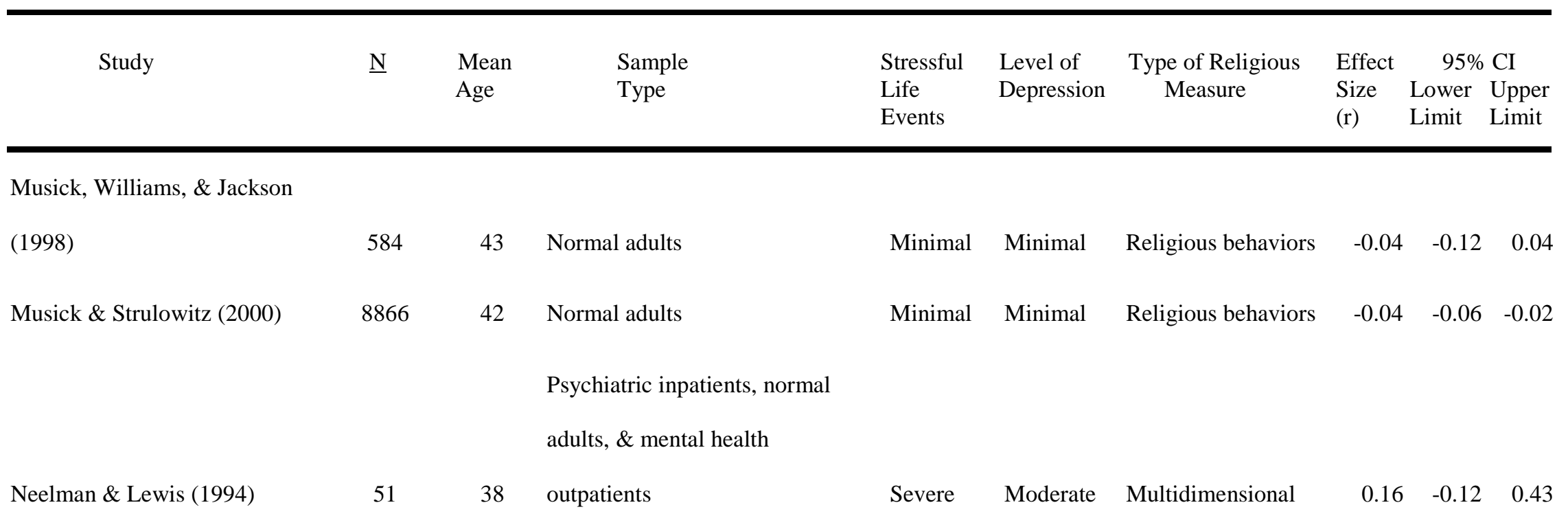


Religiousness and Depressive Symptoms 83

\begin{tabular}{|c|c|c|c|c|c|c|c|c|c|}
\hline Neff \& Hoppe (1993) & 1784 & 38 & Normal adults & Minimal & Minimal & Multidimensional & -0.13 & -0.18 & -0.08 \\
\hline Nelson (1989) & 68 & 72 & Normal adults & Minimal & Minimal & Multidimensional & -0.16 & -0.39 & 0.08 \\
\hline Nelson (1989) & 26 & 81 & Nursing home residents & Mild & Minimal & Religious behaviors & -0.39 & -0.72 & -0.06 \\
\hline O'Connor \& Vallerand (1990) & 146 & 82 & Nursing home residents & Mild & Minimal & Religious orientation & 0.08 & -0.09 & 0.24 \\
\hline O'Laoire (1997) & 88 & (Adults) & Normal adults & Minimal & Minimal & Religious behaviors & -0.36 & -0.54 & -0.18 \\
\hline Oler (1997) & 273 & 42 & Church members & Minimal & Minimal & Multidimensional & 0.04 & -0.08 & 0.16 \\
\hline Olszewski (1994) & 95 & 14 & Church members & Minimal & Minimal & Religious coping & 0.01 & -0.20 & 0.21 \\
\hline
\end{tabular}

Table 2 (continued). Descriptions of the 147 Individual Studies Included in the Meta-Analysis.

\begin{tabular}{|c|c|c|c|c|c|c|c|c|c|}
\hline Study & $\underline{\mathrm{N}}$ & $\begin{array}{l}\text { Mean } \\
\text { Age }\end{array}$ & $\begin{array}{l}\text { Sample } \\
\text { Type }\end{array}$ & $\begin{array}{l}\text { Stressful } \\
\text { Life } \\
\text { Events }\end{array}$ & $\begin{array}{l}\text { Level of } \\
\text { Depression }\end{array}$ & $\begin{array}{l}\text { Type of Religious } \\
\text { Measure }\end{array}$ & $\begin{array}{l}\text { Effect } \\
\text { Size } \\
(r)\end{array}$ & $\begin{array}{l}\quad 95 \% \\
\text { Lower } \\
\text { Limit }\end{array}$ & $\begin{array}{l}\text { o CI } \\
\text { Upper } \\
\text { Limit }\end{array}$ \\
\hline \multicolumn{10}{|l|}{ Palinkas, Wingard, \& Barret- } \\
\hline Connor (1990) & 1615 & 75 & Normal adults & Minimal & Minimal & Religious behaviors & -0.07 & $7 \quad-0.12$ & $2-0.02$ \\
\hline Park, Cohen, \& Herb (1990) a & 83 & 20 & University students & Minimal & Minimal & Multidimensional & -0.01 & -0.22 & $2 \quad 0.21$ \\
\hline Park, Cohen, \& Herb (1990) b & 83 & 20 & University students & Minimal & Minimal & Multidimensional & -0.05 & $5-0.26$ & 50.17 \\
\hline
\end{tabular}


Religiousness and Depressive Symptoms 84

Park, Murgatroyd, Waynock, \&

Spillet (1998)

Patock-Peckham, Hutchinson,

Cheong, \& Nagoshi (1998)

Plante \& Boccaccini (1997)

Pressman, Lyons, Larson, \&

Strain (1990)

Quinn, Hazen, \& Martin (1996)
263

102

19 University students

(Senior

30

adults) Medical inpatients

$72 \quad$ Normal adults

$\begin{array}{llllll}\text { Minimal } & \text { Minimal } & \text { Religious orientation } & 0.03 & -0.09 & 0.15 \\ \text { Minimal } & \text { Minimal } & \text { Multidimensional } & -0.16 & -0.35 & 0.03\end{array}$

$\begin{array}{lllll}\text { Moderate Minimal } & \text { Multidimensional } & -0.30 & -0.63 & 0.03\end{array}$

$\begin{array}{lllll}\text { Minimal Minimal Multidimensional } & -0.21 & -0.42 & 0.00\end{array}$

Table 2 (continued). Descriptions of the 147 Individual Studies Included in the Meta-Analysis.

\begin{tabular}{|c|c|c|c|c|c|c|c|c|c|}
\hline \multirow{2}{*}{ Study } & \multirow{2}{*}{$\underline{N}$} & \multirow{2}{*}{$\begin{array}{l}\text { Mean } \\
\text { Age }\end{array}$} & \multirow{2}{*}{$\begin{array}{l}\text { Sample } \\
\text { Type }\end{array}$} & \multirow{2}{*}{$\begin{array}{l}\text { Stressful } \\
\text { Life } \\
\text { Events }\end{array}$} & \multirow{2}{*}{$\begin{array}{l}\text { Level of } \\
\text { Depression }\end{array}$} & \multirow{2}{*}{$\begin{array}{l}\text { Type of Religious } \\
\text { Measure }\end{array}$} & \multirow{2}{*}{$\begin{array}{l}\text { Effect } \\
\text { Size } \\
(r)\end{array}$} & \multicolumn{2}{|c|}{$95 \% \mathrm{CI}$} \\
\hline & & & & & & & & $\begin{array}{l}\text { Lower } \\
\text { Limit }\end{array}$ & $\begin{array}{l}\text { Upper } \\
\text { Limit }\end{array}$ \\
\hline Ratanasiripong (1996) & 244 & 41 & Church members & Minimal & Minimal & Religious attitudes & 0.12 & 0.00 & 0.24 \\
\hline Renfroe (1990) & 25 & 31 & Mental health outpatients & Mild & Mild & Religious well-being & -0.21 & -0.59 & 0.17 \\
\hline Richards (1991) & 268 & 20 & University students & Minimal & Mild & Religious orientation & 0.07 & -0.05 & 0.19 \\
\hline
\end{tabular}


Religiousness and Depressive Symptoms 85

\begin{tabular}{|c|c|c|c|c|c|c|c|c|c|}
\hline Robinson \& Kaye (1994) & 17 & 65 & Caregivers of adult patients & Moderate & Mild & Multidimensional & -0.21 & -0.68 & 0.26 \\
\hline Robinson \& Kaye (1994) & 23 & 62 & Normal adults & Minimal & Minimal & Multidimensional & 0.05 & -0.37 & 0.47 \\
\hline Rosik (1989) & 159 & 64 & Grieving/ bereaved adults & Moderate & Mild & Religious orientation & 0.16 & 0.01 & 0.31 \\
\hline Ross (1990) & 401 & (Adults) & Normal adults & Minimal & Minimal & Religious attitudes & -0.12 & -0.22 & -0.02 \\
\hline Rowley (1998) & 230 & 38 & Normal adults & Minimal & Minimal & Multidimensional & 0.00 & -0.13 & 0.13 \\
\hline Ryan, Rigby, \& King (1993) & 151 & 23 & University students & Minimal & Minimal & Religious orientation & -0.12 & -0.17 & 0.05 \\
\hline Ryan, Rigby, \& King (1993) & 42 & 35 & Church members & Minimal & Minimal & Religious orientation & -0.06 & -0.36 & 0.25 \\
\hline Schoenbach, Kaplan, Grimson, & & (Adole- & & & & & & & \\
\hline \& Wagner (1982) & 136 & scents) & High school students & Minimal & Minimal & Religious attitudes & 0.18 & 0.01 & 0.34 \\
\hline Sherkat \& Reed (1992) & 156 & (Adults) & Grieving/ bereaved adults & Severe & Mild & Religious behaviors & -0.06 & -0.21 & 0.10 \\
\hline Study & $\underline{\mathrm{N}}$ & $\begin{array}{l}\text { Mean } \\
\text { Age }\end{array}$ & $\begin{array}{l}\text { Sample } \\
\text { Type }\end{array}$ & $\begin{array}{l}\text { Stressful } \\
\text { Life } \\
\text { Events }\end{array}$ & $\begin{array}{l}\text { Level of } \\
\text { Depression }\end{array}$ & $\begin{array}{l}\text { Type of Religious } \\
\text { Measure }\end{array}$ & $\begin{array}{l}\text { Effect } \\
\text { Size } \\
(r)\end{array}$ & \multicolumn{2}{|c|}{\begin{tabular}{ll}
\multicolumn{2}{c}{$95 \%$ CI } \\
Lower & Upper \\
Limit & Limit
\end{tabular}} \\
\hline \multicolumn{10}{|l|}{ Shuler, Gelberg, \& Brown } \\
\hline (1994) & 50 & 30 & Homeless adults & Severe & Moderate & Religious coping & -0.29 & -0.54 & -0.03 \\
\hline Simon (1992) & 50 & 84 & Nursing home residents & Mild & Mild & Religious behaviors & -0.14 & -0.41 & 0.14 \\
\hline
\end{tabular}


Religiousness and Depressive Symptoms 86

Snyder (1996)

Sorenson, Grindstaff, \& Turner

(1995)

Stavros (1998)

Steer \& Schut (1979)

Strawbridge, Shema, Cohen,

Roberts, \& Kaplan (1998)

Strayhorn, Weidman, \& Larson
$42 \quad$ Normal adults

(Adole-

261

88

200

2537

65 Normal adults

272

(Adults) Normal adults

$$
\text { scents) Teenage mothers }
$$

Minimal Minimal Multidimensional

$0.15 \quad-0.06$

Severe - Mild

Minimal Minimal

Religious behaviors

$-0.29 \quad-0.48 \quad-0.09$

Severe Mild

Religious behaviors

$\begin{array}{lll}-0.09 & -0.23 & 0.05\end{array}$

Minimal Minimal Multidimensional

$\begin{array}{lll}-0.04 & -0.08 & 0.00\end{array}$

Grieving/ bereaved adults \&

Teel (1993)

$113 \quad 47$ caregivers of adult patients

Mild

Mild

Multidimensional

$\begin{array}{lll}0.00 & -0.19 & 0.19\end{array}$

Table 2 (continued). Descriptions of the 147 Individual Studies Included in the Meta-Analysis.

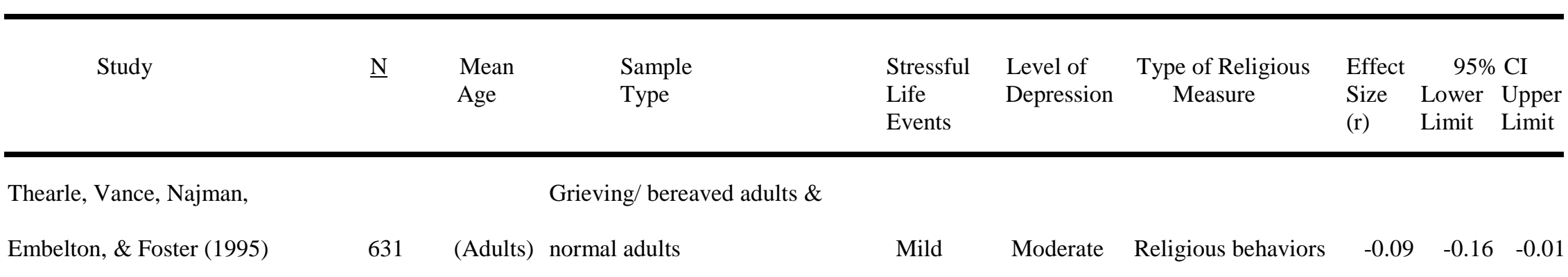


Religiousness and Depressive Symptoms 87

Trent, Keller, \& Piotrowski

(1983)

Vaillant, Meyer, Mukamal, \&

Soldz (1998)

VandeCreek, Pargament,

Belavich, Cowell, \& Friedel

Virginia (1998)

Watson, Morris, \& Hood

(1989b)

Watson, Morris, \& Hood (1989a)

1397
Minimal Minimal Religious attitudes

$-0.42 \quad-0.65$
20 University students

$50 \quad$ Normal adults

43 Caregivers of adult patients

(Adults) Religious leaders (clergy)

Minima

Minima

Minima

Minima

Multidimensional

Minimal

Minim

Religious coping
Religious behaviors

0.06

$-0.11 \quad 0.22$

Table 2 (continued). $\quad$ Descriptions of the 147 Individual Studies Included in the Meta-Analysis.

$\underline{N} \quad \begin{array}{ll}\text { Mean } & \text { Sample } \\ \text { Age } & \text { Type }\end{array}$

Study
Stressful Level of

Life

Events
Depression
Type of Religious

Measure
Effect $\quad 95 \%$ CI

Size Lower Upper

(r) Limit Limit 
Religiousness and Depressive Symptoms 88

Watson, Morris, Hood, \&

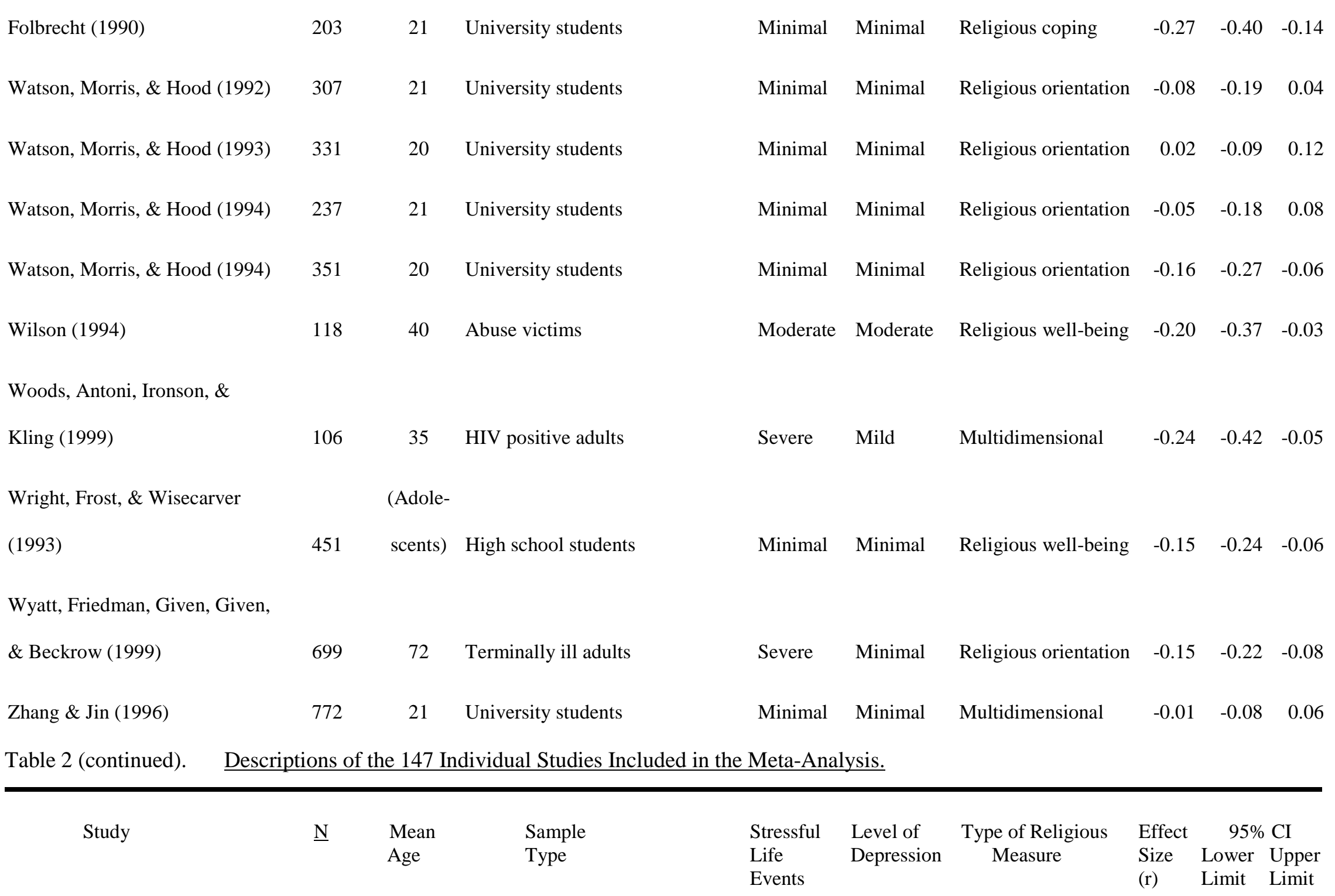


Religiousness and Depressive Symptoms 89

Zunzunegui, Beland, Llacer, \& Keller (1999)

$194 \quad 66 \quad$ Caregivers of adult patients 

Religiousness and Depressive Symptoms 91

Table 3

Weighted Mean Correlations Across Levels of Several Moderator Variables, 95\% Confidence Intervals and Amount of Between-Studies Variance Accounted For

\begin{tabular}{|c|c|c|c|c|c|c|c|c|}
\hline Variable & $\mathrm{Q}_{\mathrm{b}}$ & $\mathrm{p}$ & $\mathrm{N}$ & $\mathrm{k}$ & $\mathrm{r}_{+}$ & $95 \%$ CI & $\mathrm{Q}_{\mathrm{w}}$ & $\mathrm{p}$ \\
\hline Data Source & .15 & .70 & & & & & & \\
\hline Published & & & 66,299 & 111 & -.096 & {$[-.12,-.08]$} & 156.0 & .003 \\
\hline Unpublished & & & 32,676 & 36 & -.087 & {$[-.12,-.05]$} & 58.8 & .007 \\
\hline Gender & .001 & .98 & & & & & & \\
\hline Female & & & 19,848 & 37 & -.123 & {$[-.16,-.08]$} & 45.9 & .13 \\
\hline Male & & & 10,127 & 28 & -.122 & {$[-.17,-.08]$} & 40.3 & .05 \\
\hline Ethnicity & .51 & .78 & & & & & & \\
\hline African American & & & 5,632 & 16 & -.108 & {$[-.18,-.04]$} & 13.8 & .54 \\
\hline European American & & & 7,017 & 17 & -.073 & {$[-.15, .01]$} & 15.6 & .48 \\
\hline European (Northern) & & & 7,051 & 10 & -.105 & {$[-.19,-.02]$} & 10.0 & .35 \\
\hline Age Group & 18.9 & .009 & & & & & & \\
\hline Adolescence (13-18) & & & 6,029 & 10 & -.067 & {$[-.13,-.01]$} & 29.3 & .001 \\
\hline College-age (19-24) & & & 15,949 & 29 & -.065 & {$[-.10,-.03]$} & 27.4 & .50 \\
\hline Early adulthood (25-35) & & & 5,662 & 14 & -.092 & {$[-.15,-.03]$} & 9.7 & .72 \\
\hline Middle-age (36-45) & & & 35,751 & 37 & -.098 & {$[-.13,-.06]$} & 53.7 & .03 \\
\hline Middle-age (46-55) & & & 4,299 & 9 & -.050 & {$[-.12, .02]$} & 7.9 & .44 \\
\hline Late adulthood (56-65) & & & 6,621 & 11 & -.023 & {$[-.09, .04]$} & 6.6 & .76 \\
\hline Retirement age (66-75) & & & 24,124 & 30 & -.155 & {$[-.19,-.12]$} & 54.6 & .003 \\
\hline Elderly adults (76 +) & & & 540 & 7 & -.093 & {$[-.20, .01]$} & 4.6 & .60 \\
\hline
\end{tabular}

(Table 3 continues) 
Table 3 (Continued)

\begin{tabular}{|c|c|c|c|c|c|c|c|c|}
\hline Variable & $\mathrm{Q}_{\mathrm{b}}$ & $\underline{p}$ & $\mathrm{~N}$ & $\mathrm{k}$ & $\mathrm{r}_{+}$ & $95 \% \mathrm{CI}$ & $\mathrm{Q}_{\mathrm{w}}$ & $\mathrm{p}$ \\
\hline Inferred Life Event Stress & 15.9 & .0004 & & & & & & \\
\hline Minimal & & & 88,139 & 90 & -.071 & {$[-.09,-.05]$} & 116.1 & .03 \\
\hline Mild to Moderate & & & 5,785 & 32 & -.141 & {$[-.18,-.10]$} & 50.7 & .01 \\
\hline Severe & & & 5,051 & 25 & -.152 & {$[-.20,-.11]$} & 38.5 & .03 \\
\hline Inferred Depression & 10.0 & .007 & & & & & & \\
\hline Minimal & & & 87,357 & 104 & -.078 & {$[-.10,-.06]$} & 134.3 & .02 \\
\hline Mild & & & 5,748 & 25 & -.135 & {$[-.18,-.09]$} & 43.3 & .01 \\
\hline Moderate & & & 5,870 & 18 & -.151 & {$[-.21,-.10]$} & 31.1 & .02 \\
\hline Measure of Religiousness & 170.5 & $<.0001$ & & & & & & \\
\hline Religious Behaviors & & & 43,572 & 30 & -.124 & {$[-.16,-.09]$} & 34.2 & .23 \\
\hline Religious Attitudes/Beliefs & & & 16,725 & 18 & -.053 & {$[-.10,-.01]$} & 35.4 & .006 \\
\hline \multicolumn{9}{|l|}{ Religious Orientation } \\
\hline Intrinsic & & & 4,445 & 22 & -.175 & {$[-.22,-.13]$} & 53.8 & .0001 \\
\hline Extrinsic & & & 6,361 & 23 & .155 & {$[.11, .20]$} & 30.2 & .11 \\
\hline \multicolumn{9}{|l|}{ Religious Coping } \\
\hline Positive & & & 2,274 & 11 & -.167 & {$[-.24,-.10]$} & 7.8 & .65 \\
\hline Negative & & & 1,999 & 8 & .136 & {$[.06, .21]$} & 8.4 & .30 \\
\hline Religious Well-being & & & 2,106 & 11 & -.197 & {$[-.27,-.12]$} & 24.5 & .006 \\
\hline God Concept & & & 1,352 & 4 & -.199 & {$[-.31,-.09]$} & 4.4 & .22 \\
\hline Multidimensional & & & 28,345 & 51 & -.095 & {$[-.13,-.06]$} & 37.4 & .91 \\
\hline
\end{tabular}

Note. $\mathrm{Q}_{\mathrm{b}}=\mathrm{Q}$-value for variance between groups. $\mathrm{Q}_{\mathrm{w}}=\mathrm{Q}$-value for variance within groups. 
Table 4

$\underline{\text { Random Effects Regression Weights for Study Characteristics Associated with Effect Sizes }}$

\begin{tabular}{|c|c|c|c|c|}
\hline Variable & $\mathrm{B}$ & SE & $p$ & $\beta$ \\
\hline Constant & -.094 & .017 & $<.0001$ & .00 \\
\hline \multicolumn{5}{|l|}{ Demographics } \\
\hline Gender & -.001 & .001 & .74 & -.02 \\
\hline Ethnicity & .001 & .001 & .49 & .04 \\
\hline Age & -.001 & .001 & .34 & -.06 \\
\hline \multicolumn{5}{|l|}{ Participant Distress } \\
\hline Stressful Life Events & -.012 & .017 & .47 & -.05 \\
\hline Depression & -.005 & .018 & .78 & -.02 \\
\hline \multicolumn{5}{|l|}{ Measures of Religiousness } \\
\hline Religious Behaviors & -.030 & .027 & .27 & -.07 \\
\hline Religious Attitudes & .032 & .032 & .31 & .06 \\
\hline Intrinsic Religious Orientation & -.084 & .031 & .007 & -.16 \\
\hline Extrinsic Religious Orientation & .239 & .031 & $<.0001$ & .46 \\
\hline Positive Religious Coping & -.078 & .042 & .08 & -.10 \\
\hline Negative Religious Coping & .230 & .044 & $<.0001$ & .28 \\
\hline Religious Well-being & -.111 & .043 & .01 & -.14 \\
\hline God Concept & -.103 & .062 & .10 & -.09 \\
\hline
\end{tabular}


Religiousness and Depressive Symptoms 94

\section{Figure Caption}

Figure 1. Plot of effect sizes (Pearson $\underline{\mathrm{r}}$ ) as a function of sample size (log). 
Figure 1

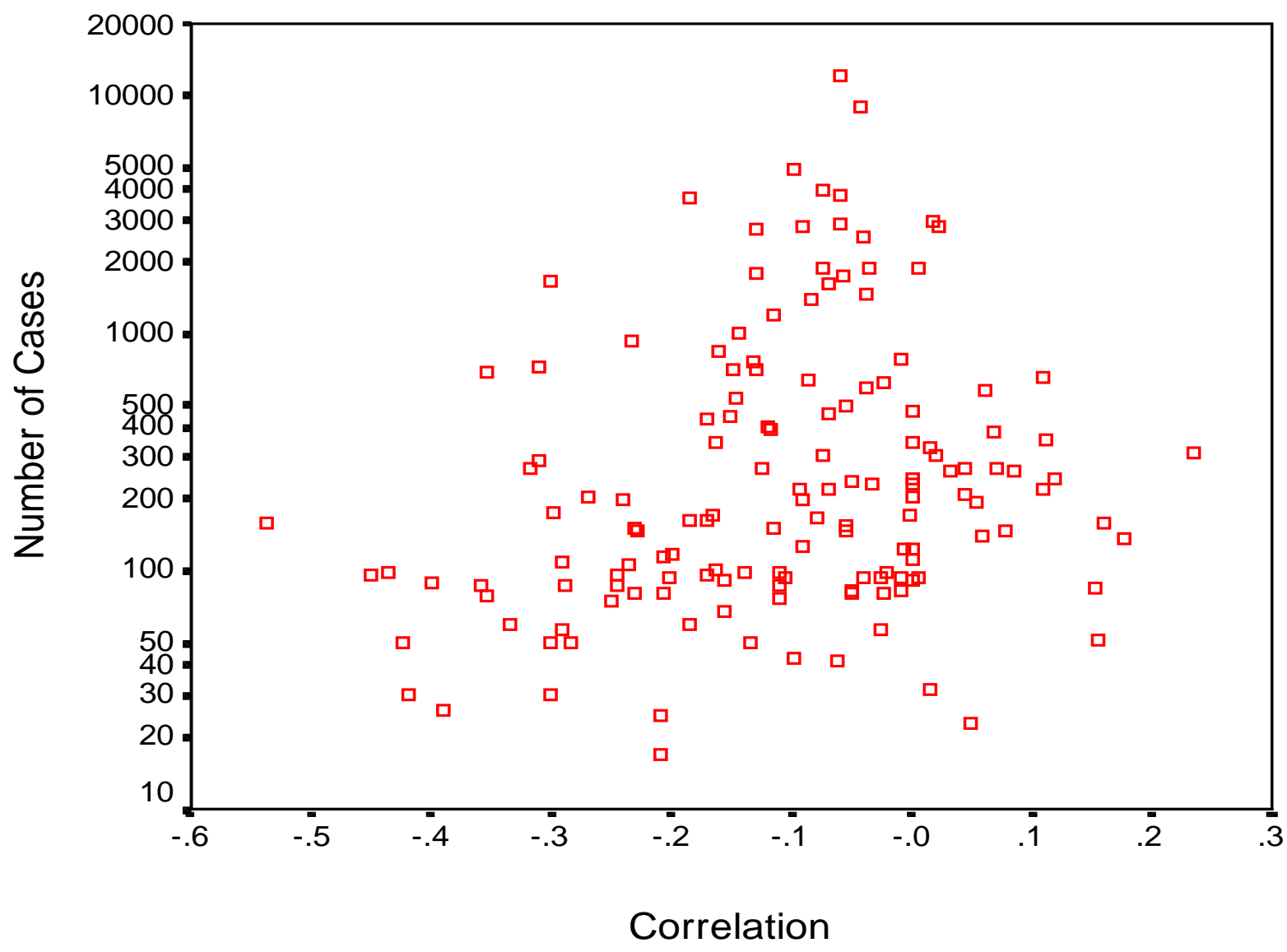

